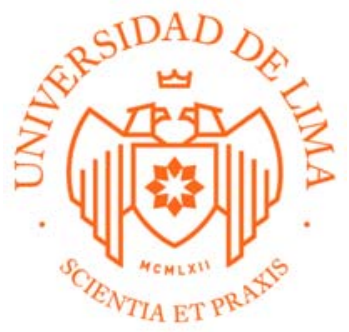

\title{
LÁTEX: PROYECTO DE EXPOSICIÓN FOTOGRÁFICA SOBRE LA IDENTIDAD Y EL ROL DEL MODELO
}

Trabajo de Suficiencia Profesional para optar el Título Profesional de Licenciado en Comunicación

\section{Ilan Ricardo Valdes Querol}

Código 20141378

\author{
Asesor \\ José David García Contto
}

Lima - Perú

Febrero de 2020 


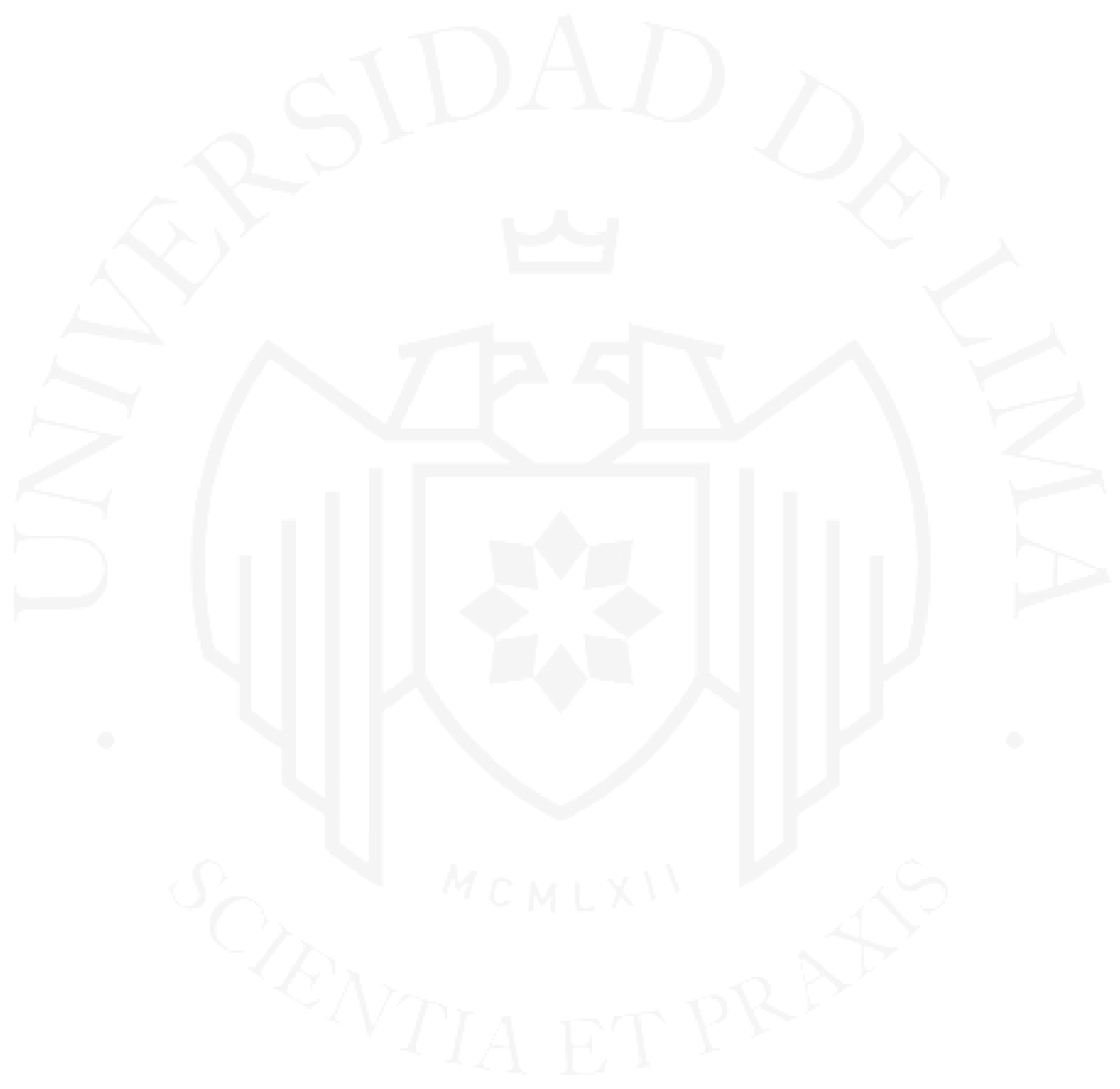




\section{LÁTEX: PROYECTO DE EXPOSICIÓN FOTOGRÁFICA SOBRE LA IDENTIDAD Y EL ROL DEL MODELO}




\section{TABLA DE CONTENIDO}

RESUMEN EJECUTIVO_............................................................................. ix

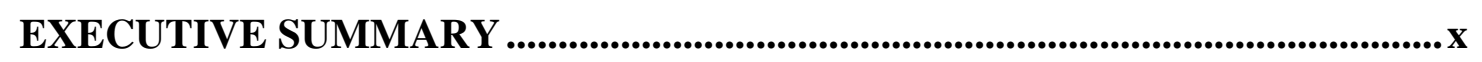

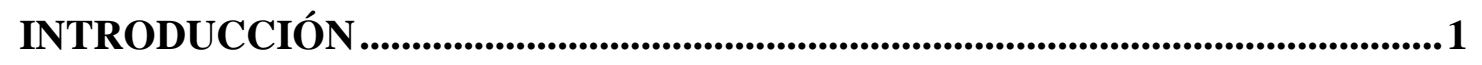

CAPÍTULO I: ANTECEDENTES DEL TRABAJO .............................................3

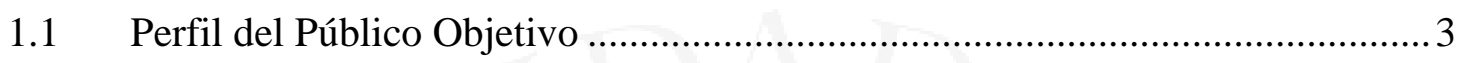

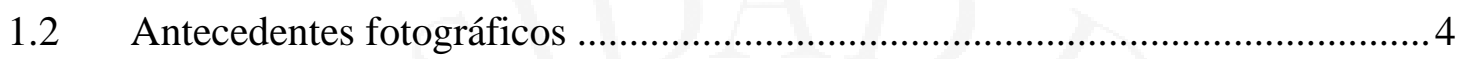

CAPÍTULO II: REALIZACIÓN O INTERVENCIÓN ............................................12

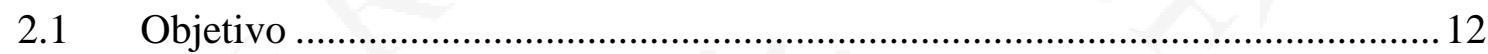

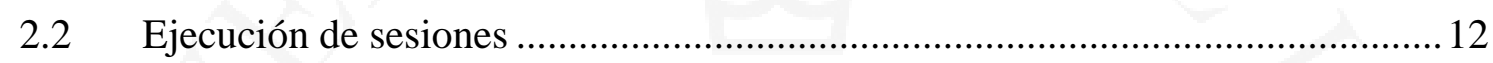

CAPÍTULO III: SUSTENTACIÓN .............................................................................24

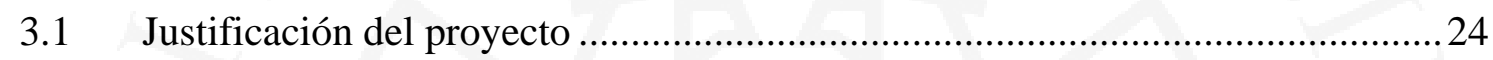

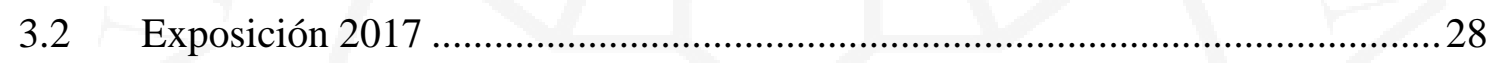

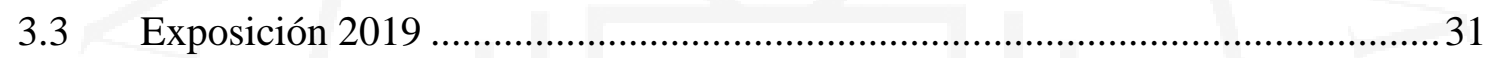

CAPÍTULO IV: LOGROS Y RESULTADOS ........................................................ 34

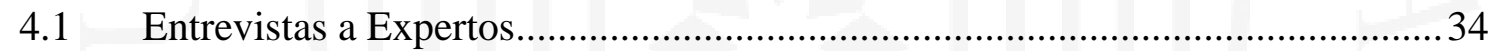

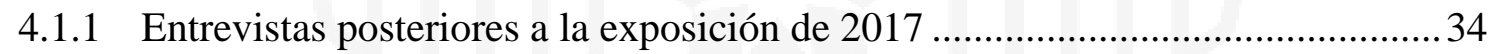

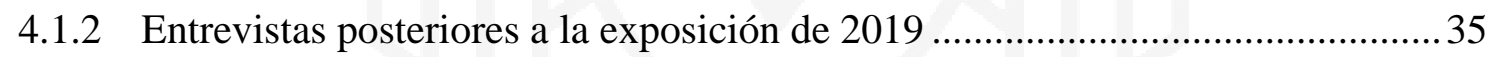

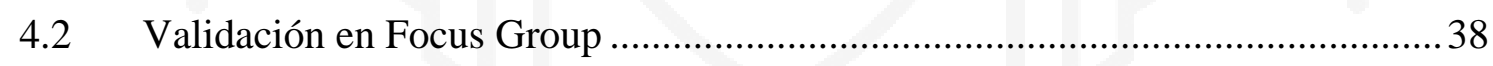

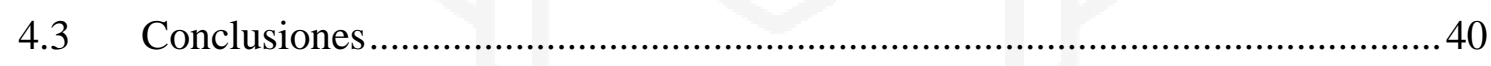

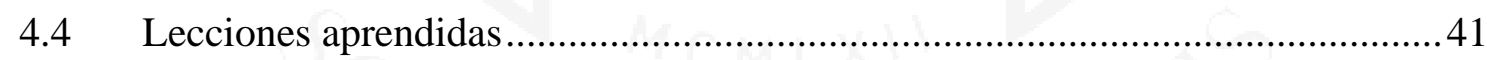

REFERENCIAS

¡ER

ROR! MARCADOR NO DEFINIDO. 


\section{ÍNDICE DE TABLAS}

Tabla 3.1 Relación de factores alterados por sesión fotográfica realizada......................26 


\section{ÍNDICE DE FIGURAS}

Figura 1.1 Fotografía realizada por Macarena Puelles .................................................. 4

Figura 1.2 Autorretratos de Nadir Cárdenas............................................................... 5

Figura 1.3 Fotografías de serie Betelgeuse de Igor Pjörrt ............................................ 5

Figura 1.4 Fotografías del 365 day project de Alex Stoddard........................................ 6

Figura 1.5 Fotografías de la serie UMBRA de Vivianne Sassen ................................... 7

Figura 1.6 Fotografías de la serie Tryouts de Ryan James Caruthers.............................. 7

Figura 1.7 Fotografías de la serie Serenity de Can Dagarslani...................................... 8

Figura 1.8 Fotografías de Stephen Medeiros .............................................................. 9

Figura 1.9 Fotografías de serie RUSH de Regis Cebrián ............................................ 9

Figura 1.10 Fotografía de Evelyn Bencicova ............................................................. 10

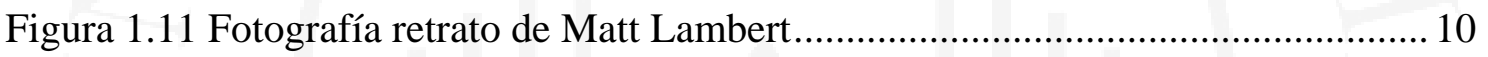

Figura 1.12 Fotografías de serie My Depression de Ren Hang .................................... 11

Figura 1.13 Fotografia instantánea de Nan Goldin .................................................... 11

Figura 2.1 Mosaico visual de primeros retratados por columna.................................... 13

Figura 2.2 Fotografía de sesión realizada a Lorena Blume .......................................... 13

Figura 2.3 Fotografia de sesión realizada a Diana Chávez............................................ 14

Figura 2.4 Fotografía de sesión realizada a Matías Campá............................................. 15

Figura 2.5 Fotografía de sesión realizada a Sebastián Ortiz de Zevallos ........................ 15

Figura 2.6 Fotografía de sesión realizada a Sofía Caravedo ....................................... 16

Figura 2.7 Fotografía de sesión realizada a Camila Varela .......................................... 17

Figura 2.8 Mosaico visual de extensión fotográfica por columna................................ 18

Figura 2.9 Fotografía de sesión realizada a Laia Ruiz de Eguilaz ................................ 19

Figura 2.10 Fotografía de sesión realizada a Carolina Anaya ........................................ 19

Figura 2.11 Fotografía de sesión realizada a Camila Guerrero ..................................... 20 
Figura 2.12 Fotografía de sesión realizada a Diego Perez Chirinos.............................. 21

Figura 2.13 Fotografía de sesión realizada a Laura Alegre.......................................... 21

Figura 2.14 Fotografía de sesión realizada a Sebastián Palacios ................................... 22

Figura 2.15 Fotografía de sesión realizada a Danelle Larrabure .................................... 23

Figura 3.1 Disposición de exposición en 2017 .............................................................28

Figura 3.2 Elementos de difusión del evento en el Club Regatas ................................. 30

Figura 3.3 Disposición inicial de exposición en 2019.................................................... 31

Figura 3.4 Disposición final de exposición en 2019 .................................................... 32

Figura 3.5 Vista bilateral de exposición de 2019 ........................................................ 32

Figura 3.6 Evidencia de interacción en redes por vínculo de cuenta .............................33 


\section{ÍNDICE DE ANEXOS}

Anexo 1 Formato de consentimiento 48 


\section{RESUMEN EJECUTIVO}

El proyecto consiste en una serie fotográfica: LÁTEX, compuesta de grupos de imágenes que se concentran en la búsqueda de la esencia artificial (conjunto de características que el fotografiado busca proyectar). La propuesta está condicionada a la idea de que los fotografiados se deben diferenciar en tanto proponen una estética única en relación a las demás. Se busca la participación activa del modelo en la construcción de la estética respondiendo así a la pregunta ¿Pueden plasmarse las características artificiales de las personas en un proyecto fotográfico con muestras que se diferencien entre ellas y mantengan unidad?

Palabras clave: Fotografía, Identidad, Modelo, Rol, Estética, Humanismo. 


\section{EXECUTIVE SUMMARY}

The project consists in a photographic series, LATEX, made up of multiple volumes that focus on the contemporary search of the artificial essence (set of features that the photographed seeks to project). The approach is conditioned by the idea that every volume is differentiated as it proposes a unique aesthetic in relation to the previous one. The project seeks the participation of the model in the construction of aesthetics, thus answering the following question: Can you capture the artificial characteristics of people in a photographic project with samples that differ between themselves but maintain unity?

Keywords: Photography, Identity, Model, Role, Aesthetic, Humanism. 


\section{INTRODUCCIÓN}

"Tomo fotografías para saber qué

aspecto tengrá algo una vez fotografiado”

- Garry Winogrand

Cuando el proyecto de Látex comenzó en 2016, tenía la finalidad de retratar a personas buscando su esencia artificial, es decir, el conjunto de características tanto "naturales” como artificiales que el sujeto deseaba proyectar. A medida que se comenzaba a retratar a más personas, se encontraban patrones en la composición que se repetían. Fue así que se optó por forzar este proceso buscando que las sesiones se diferencien entre ellas. Para concretar esto, se buscó que cada modelo responda a un color, composición y entorno diferente de acuerdo a las características que ellos mismos identificaban y sentían que los hacían únicos.

Se propuso, entonces, realizar una serie fotográfica en la que cada sesión se diferencie de la anterior en tanto se capture la esencia de lo que el individuo quiera transmitir manteniendo una unidad general en la muestra final. Para esto era importante encontrar patrones o elementos artísticos que se desplieguen en forma de una representación única por sesión.

Fue así como surge la idea de una identidad conjunta que pueda ser inmortalizada en la forma de una muestra y que esta, a su vez, tenga su origen en un concepto con propiedades expandibles para su futura continuación. Así, podría explorar y reflexionar alrededor del rol de los modelos y la identidad en las series fotográficas.

En el 2017 se realizó una muestra que expone a seis retratados en una exposición conjunta que se instaló en el Club Regatas por más de dos semanas. Una vez culminada la muestra, se realizaron entrevistas a expertos en la comunicación audiovisual con el fin de recibir feedback y volver a realizar la muestra. Se incorporaron mejoras a partir de estas entrevistas, como una metodología más clara previa a la sesión con el fin de perpetuar la participación activa de los modelos en su sesión y reivindicar su papel en el proceso. Finalmente, en el 2019 se vuelve a montar la exposición en la Universidad de Lima, con seis retratados nuevos que expanden el universo ficcional construído. 
Esta exposición se pone a prueba en un focus group con estudiantes donde los participantes logran identificar "islas", o grupos pequeños, donde se distinguen las diferencias entre las series fotográficas. A pesar de esto, se reconoce un sesgo metodológico a la hora de buscar cambiar la perspectiva de un mismo fotografiado desde una estructura comparativa que se propone proyectar un diferencial en la identidad del sujeto que lo precede desde una misma mirada. 


\section{CAPÍTULO I: ANTECEDENTES DEL TRABAJO}

\subsection{Perfil del Público Objetivo}

Tomando en cuenta las catacterísticas del público identificado en los antecedentes, podemos tomar en consideración el hecho de que el grupo objetivo, en primera instancia, debe tener interés en la producción de índole artístico. En ese sentido se podría especular en torno a la idea de la necesidad de educarse en el plano visual.

Es importante notar que el incremento del poder adquisitivo de la clase media a nivel nacional (Perú 21, 2015), que analiza el estudio nacional del consumidor peruano (ENCP, 2017) con la finalidad de analizar la reducción en las brechas económicas a nivel provincial, identifica seis tipos de perfiles de consumidores peruanos: dentro de estos la fotografía artística contemplaría a un grupo con estilo de vida Sofisticado (10\%), y Formal (20\%).

Con esto, hacemos referencia al hecho de que hay una mayor predisposición de parte de compradores jóvenes, innovadores y de mentalidad abiertas dispuestos a “diferenciarse”. Tenemos también a los grupos formales que buscan el mantenimiento de un status quo y que, a pesar de su apego hacia lo tradicional, invierten en aspectos que ayuden a fortalecer la imagen determinada que quieran proyectar.

Asimismo, como menciona Sánchez en el diario Gestión (2017), el consumidor peruano está cambiando gracias a la globalización. De esta manera, de los cerca de 10,2 millones de 'millennials' a nivel nacional, el 92\% por ciento cuenta con una red social y se conecta por lo menos 7 veces al día (Sánchez, 2017). Tiene sentido, entonces, expandir la serie a través de redes para llegar a un público más joven: pensar, ya no en un público fijo, sino en uno que usa activamente la tecnología. Con esto en mente es pertinente evaluar mecanismos online para explotar el potencial del proyecto.

Finalmente, según los estudios sobre la evolución de la pobreza del INEI (2017), la mayor variación porcentual positiva del gasto real viene del ámbito de recreación y cultura. El incremento de 9,6 hace que este ámbito se contemple dentro de un marco de "Diferencia muy altamente significativa”. Para la estratificación del grupo objetivo este dato es crucial ya que evidencia un creciente interés de la población por tener acceso a canales de difusión cultural. 


\subsection{Antecedentes fotográficos}

Con la finalidad de entender cómo concibe el fotógrafo al sujeto en la actualidad, recojo algunas muestras que ayudan a ilustrar cómo la participación del sujeto no suele estar condicionada a la noción de identidad que el fotógrafo registra, sino que responde más bien a una exploración lineal que construye un sentido conjunto. La fotografía responde así a una exploración de la identidad que encuentra el sentido en un hilo conceptual que agrupa y diferencia las piezas de un grupo para su posterior desconstrucción y entendimiento.

Es importante tomar en consideración que, dada la naturaleza exploratoria de las sesiones, no todas las referencias son tomadas en cuenta para la ejecución de la totalidad del proyecto.

1. “Para Elisa”- Macarena Puelles: Salón Espacio del 10 de enero al 10 de febrero de 2018. “Lejos de tomar un papel pasivo en el momento de la creación, es la musa quien toma control de la situación y juega en complicidad con la artista al momento del acto fotográfico” (Peru 21, 2018). Puelles es una fotógrafa peruana pionera en retrato exclusivamente femenino en el Perú. Su propuesta es extraer una feminidad reinterpretada que se desprende de prejuicios y modelos de belleza clásicos proponiendo un canon libre de prejuicios con un enfoque humanista donde el sujeto se expone como parte de un proceso de aceptación y reacoplamiento. (Jiménez, 2016)

\section{Figura 1.1}

Fotografía realizada por Macarena Puelles

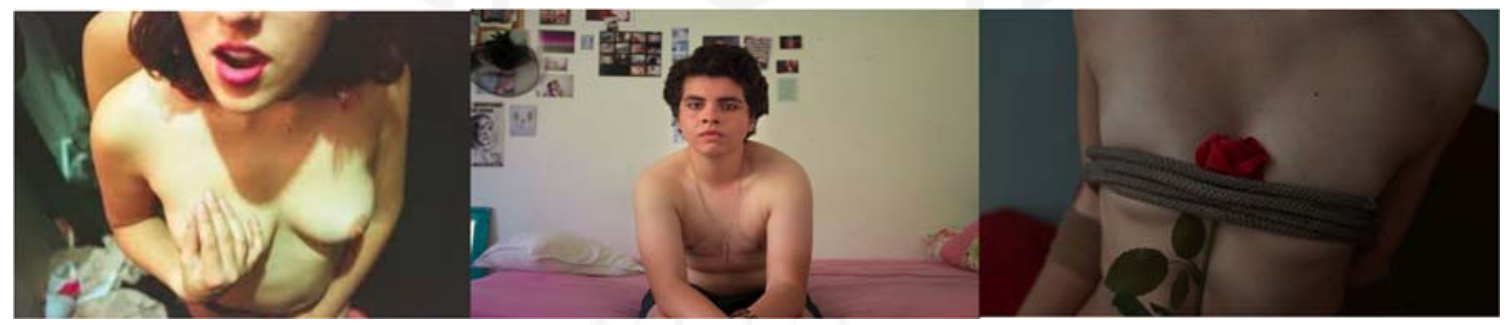

Fuente: Puelles (2016)

2. “Foto de Perfil” - Nadir Cárdenas: Expuesto en Cine Olaya el 21/04/2018. Serie de autorretratos de la fotógrafa que tiene el proyecto hace nueve años. Busca hablar del “narcisismo saludable” independientemente de la forma de tu cuerpo y tus características (Cárdenas, 2016). Esta serie nos propone una propuesta más naturalista y desprendida de una dirección de arte compleja con la intención de centrarse en el sujeto. La 
incorporación de este antecedente al proyecto responde a la exploración serial de la construcción desde un enfoque documental que responda al sujeto retratado.

Figura 1.2

Autorretratos de Nadir Cárdenas
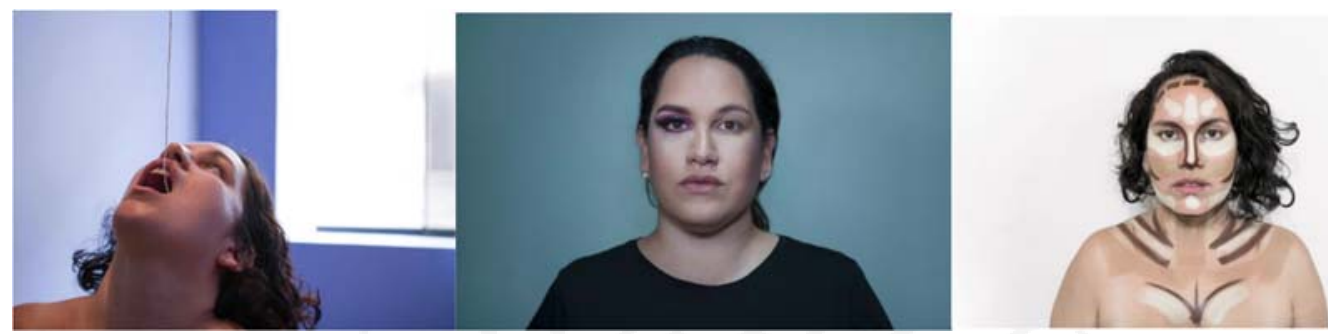

Fuente: Cárdenas (2016)

3. Igor Pjörrt - "Betelgeuse” - Habla de cómo su experiencia lo hace simpatizar con los miedos y las visiones que comparte con el modelo, y cómo, a través de la vulnerabilidad y la desvergüenza, pudieron encontrar un vínculo en la intimidad (Pjörrt, 2016). Pjörrt ha sido una gran influencia, en tanto parte de la intimidad para llevar a cabo sus proyectos. Al posicionar a sus personajes en entornos cotidianos su proyecto se convierte en una serie artística de carácter rutinario, idea que está intrínsecamente vinculada a la propuesta de "Látex” en tanto se busca incorporar la cotidianidad para reinterpretarla.

Figura 1.3

Fotografías de serie Betelgeuse de Igor Pjörrt

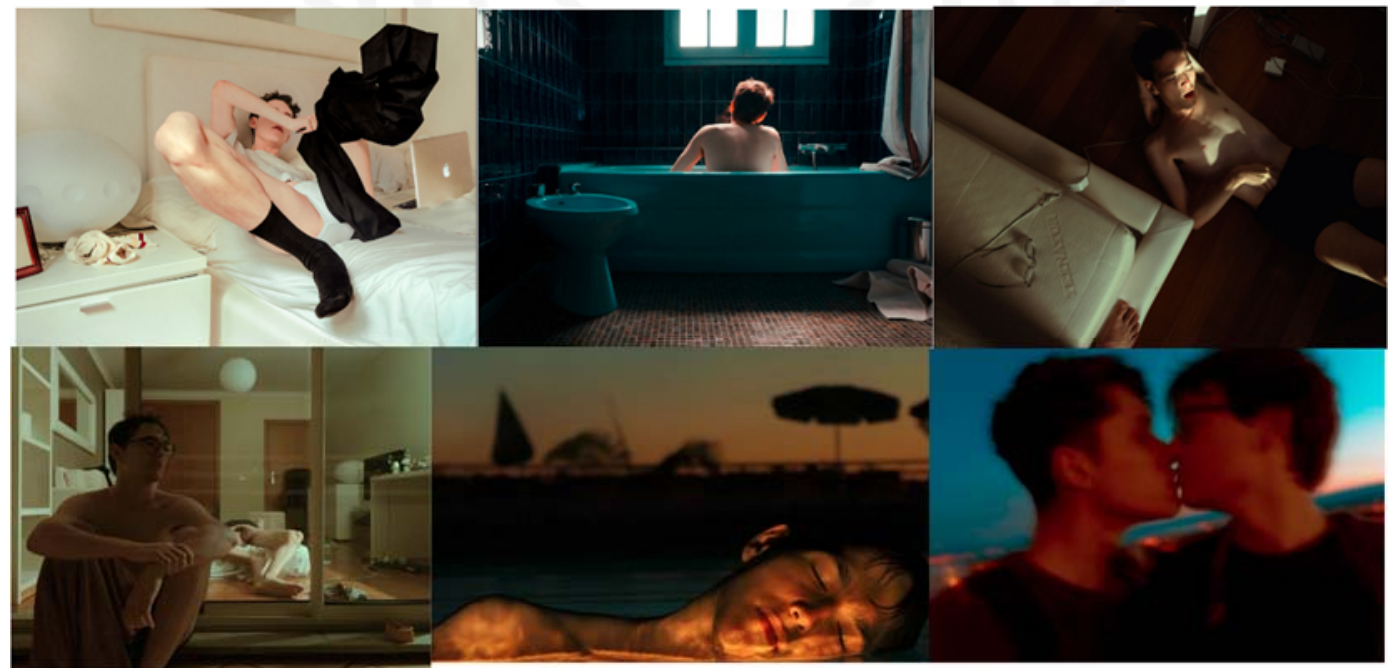

Fuente: Pjörrt (2016)

4. Alex Stoddard: “365 day project” en Flickr. El proyecto consistió en un autorretrato al día por un año. Él salía al bosque hasta acabar sus fotos y buscaba evidenciar no solo su mejora continua, sino también capturar sus emociones a lo largo de un periodo. Lo más 
interesante de esta serie es que está constituida por piezas independientes que se diferencian comparativamente (Jarvis, 2012). Stoddard propone además un vínculo con la naturaleza muy estrecho en el que entorno se convierte en un personaje activo en la narrativa surreal y construcción del imaginario. El formato de 1x1 ayuda mucho en tanto su composición es bastante simétrica. Su propuesta visual se relaciona con Látex habida cuenta de que el entorno debe incorporarse y ser tomado en cuenta como elemento para el desarrollo de una licencia ficcional de corte surrealista tal como sucede en la serie de Diana Chávez.

Figura 1.4

Fotografías del 365 day project de Alex Stoddard
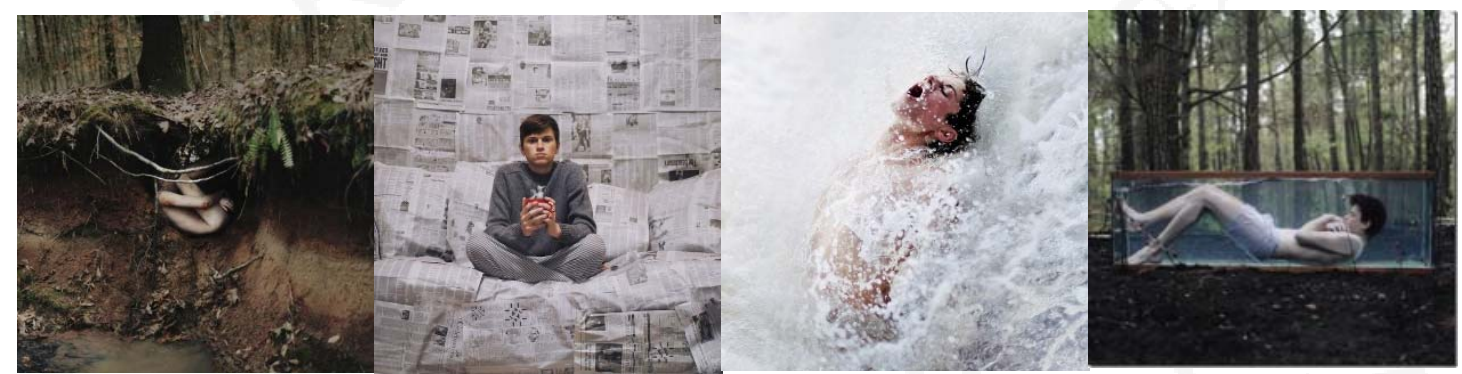

Fuente: Stoddard (2018)

5. Viviane Sassen "UMBRA": Este serie de fotos contrasta la naturaleza con las formas y usa estas para potenciar su discurso. Hace uso de la latencia y la ausencia como elementos claves para la composición. El uso de sombras para esconder información en contraste con la luz es recurrente en su trabajo. En el trabajo de Sassen la identidad pasa a un segundo plano para priorizar aspectos conceptuales que se plantean desde el uso de una geometría acompañada de colores análogos (Napolitano, 2017). Adicionalmente, se recoge el uso de la luz y su refracción como metáfora discursiva para apelar a los conceptos de identidad y proyección. En Látex, la geometría como recurso se puede ver, por ejemplo, en la sesión realizada con Sofía Caravedo en Iquitos. 
Figura 1.5

Fotografías de la serie UMBRA de Vivianne Sassen

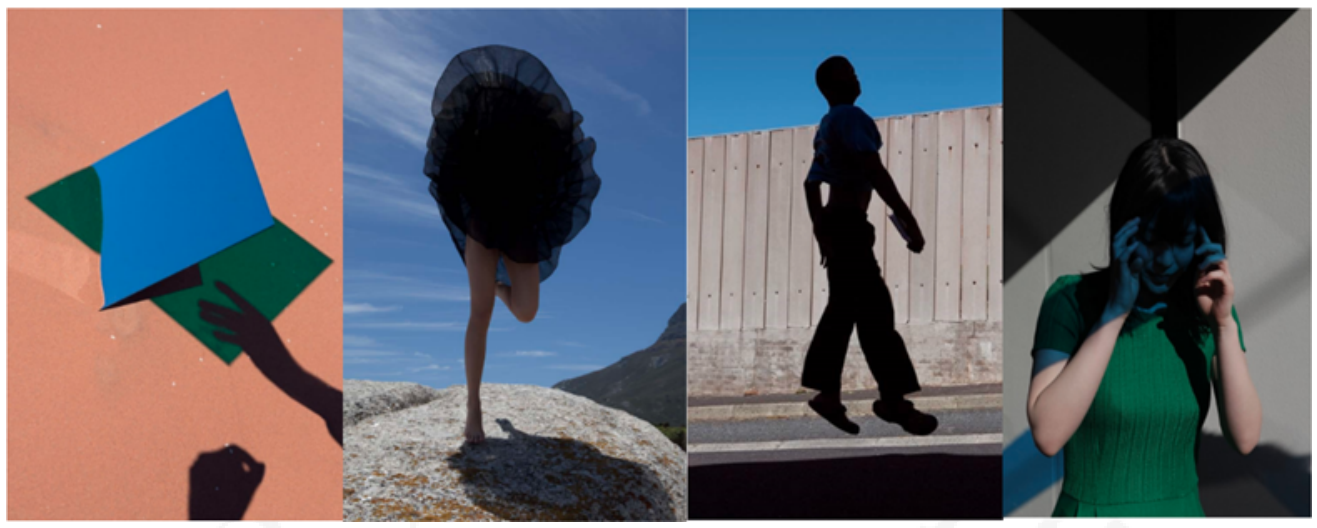

Fuente: Sassen (2020)

6. Ryan James Caruthers, "Tryouts": La serie recoge las experiencias personales del fotógrafo y su infancia en New Jersey. Busca comunicar la experiencia de crecer sin encajar en las normas sociales. Con esta idea, su trabajo es una reflexión sobre la fragilidad de la masculinidad y la identidad en relación con la homosexualidad, el deporte y el "bullying" (Mroz, 2016). Este discurso se refleja en el contenido, la composición y la paleta de colores. Esta serie, al igual que la de Alex Stoddard, también tiene una relación independiente entre las piezas, sin embargo, aparece un hilo conductor más concreto al haber una temática detrás. Caruthers tiene una aproximación más conceptual y menos documental, enfocándose con mayor agudez en elementos que responden a la construcción de la crítica. (Mohhamed, 2016)

Figura 1.6

Fotografías de la serie Tryouts de Ryan James Caruthers
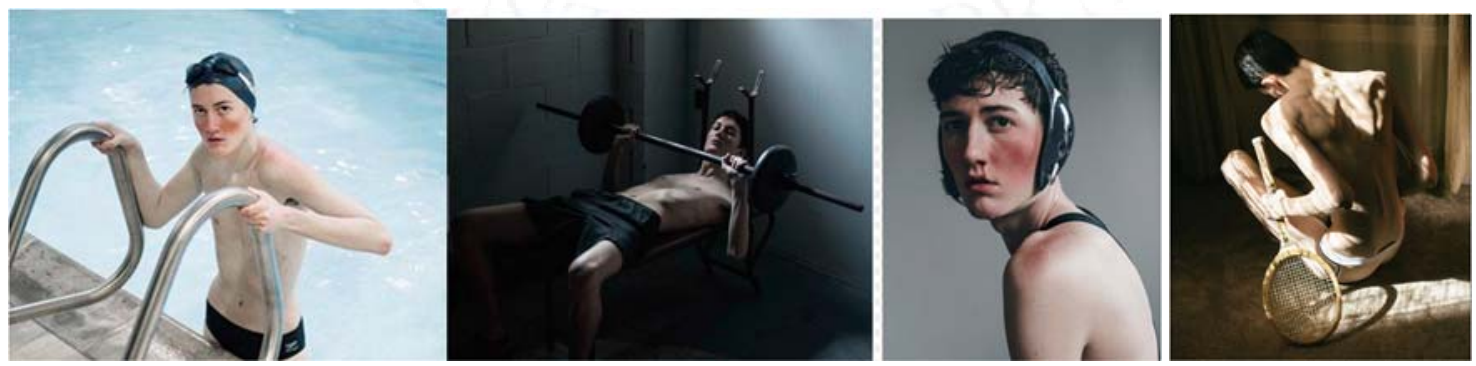

Fuente: Caruthers (2016)

7. Can Dagarslani, “Serenity” (2016): Dagarslani estudia la relación de la fotografía y la arquitectura con respecto a las emociones y los límites de la sociedad en torno a la 
identidad. Para establecer una relación entre la vejez y la serenidad. Para llevarla a cabo se utiliza la paleta de colores de Bauhaus (triada) y elementos que, en contraste con la luz, juegan un papel simbólico en el contenido. La relación entre los elementos que aparecen en la imagen genera una asociación entre la tercera edad y la serenidad que, sin ser evidente, queda clarísima para el espectador. Esta sutileza en la utilización de elementos complementarios a la imagen es justamente la clave de su esencia. (Mróz, 2016). Es la sesión de Matías Campá, por ejemplo, resulta crucial la incorporación de elementos relacionados al brutalismo y el desgaste para hacer alusión al paso del tiempo. La sesión se realizó por esos motivos en la Residencial San Felipe, donde el espacio cumplía un rol activo.

Figura 1.7

Fotografías de la serie Serenity de Can Dagarslani
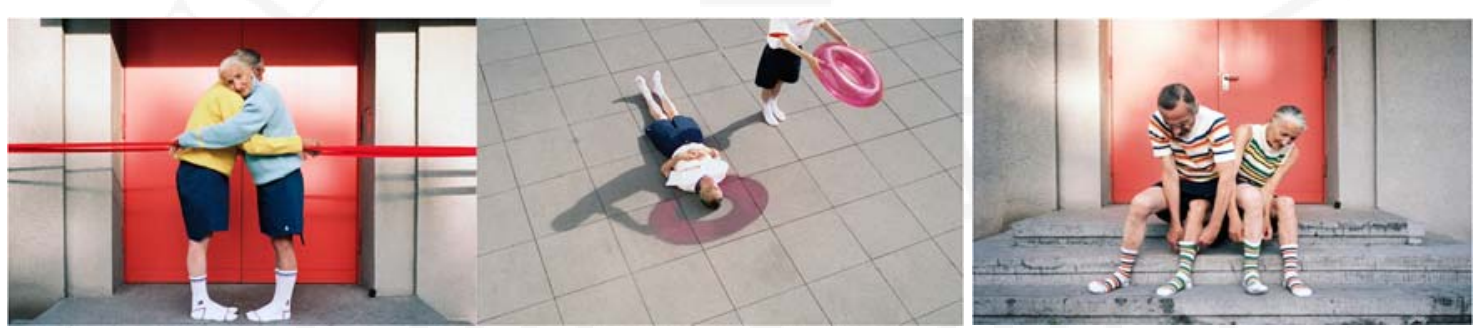

Fuente: Dagarslani (2016)

8. Stephen Medeiros: Medeiros es un joven fotógrafo que hace autorretratos a través de los cuales experimenta con técnicas artísticas que se trasladan a ámbitos que transitan desde el arte de la imagen hasta las áreas más gestuales. El objetivo final es capturar los detalles ilógicos de los sujetos en entornos surrealistas. El fotógrafo experimenta con diferentes técnicas en el arte que se convierten en las protagonistas de la propuesta (Stone, 2015). Esta serie de retratos contrasta especialmente con la de Nadir Cárdenas en la que el arte no tiene una función predominante en el contenido. El sujeto es el portador de los elementos externos pero estos no están en disposición de realzarlo sino de esconderlo. Ambas propuestas igualmente válidas con resultados distintos. En Látex, esta referencia, y uso particular del discurso visual, se evidencia en la serie de Camila Valera realizada en las Lomas de Lúcumo donde el sujeto es escondido con el fin de que, al pasar a un segundo plano, se recupere el protagonismo perdido. 
Figura 1.8

Fotografías de Stephen Medeiros
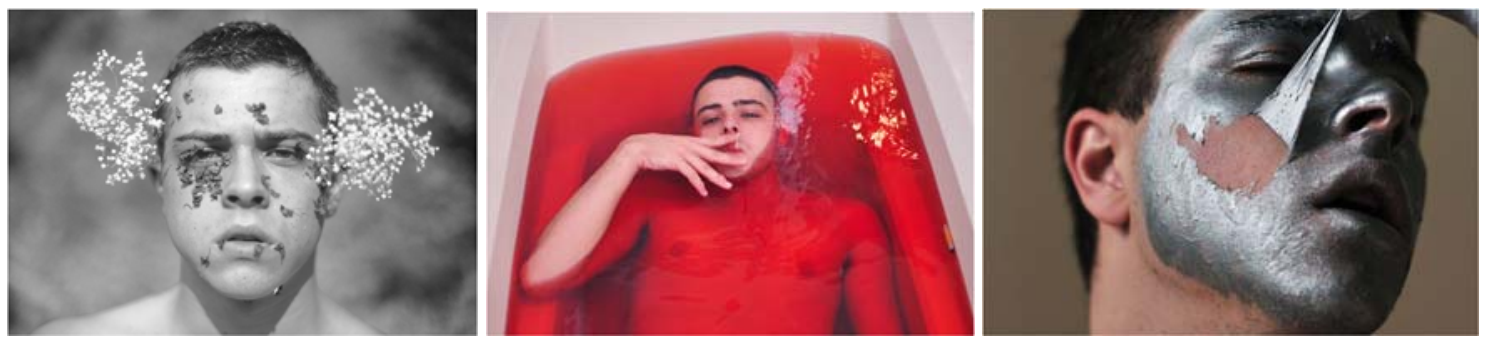

Fuente: Medeiros (2015)

9. Regis Cebrián "RUSH”: El fotógrafo peruano basa su trabajo en retratos del entorno social. Busca que haya absoluta libertad a lo largo de todo el proceso creativo. Se busca que el espectador decodifique la obra con la misma mirada libre interpretando de múltiples maneras una misma imagen. La serie "RUSH" retrata el recorrido del orgasmo de una serie de hombres en una serie de tres o dos piezas cada una (Cebrian, 2016). Al igual que en el trabajo de Ryan James Caruthers hay un hilo conductor conceptual, sin embargo, los sujetos varían de pieza en pieza tal como sucede en Látex.

Figura 1.9

Fotografías de serie RUSH de Regis Cebrián
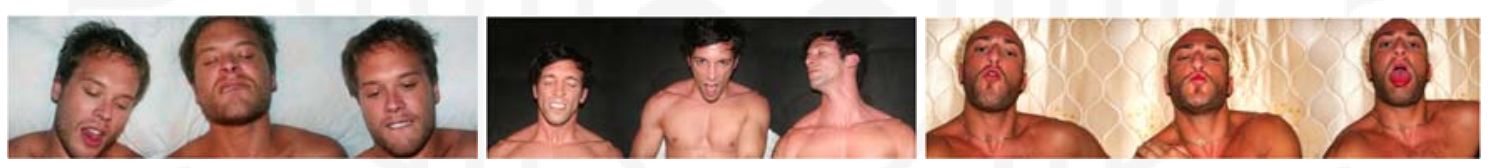

Fuente: Cebrian (2016)

10. Evelyn Bencicova "Zvernovka”: Evelyn Benvicova, en todas sus series (“Artificial tears”, “Close”, “The observer”, “Alice”, “Taste of leaving”, etc.), evita mostrar las caras y compone de tal manera que los personajes se pierden en el fondo y su identidad es esquiva. Usa la luz para esconder y capas de tela o plástico para difuminar a sus retratados. La uniformidad de los colores desaturados ayuda a asociar libremente el grupo de fotografías. Bencicova trabaja mucho con poca profundidad de campo, fondos pintados y sujetos con una dirección de arte muy cuidada. El sujeto existe en tanto se mimetiza con el fondo perdiendo su identidad y dándole protagonismo a los elementos externos en relación a la enteridad de la pieza (Bencicova, 2017). En la sesión realizada con Lorena Blume, por ejemplo, se buscó reducir la profundidad de campo con esa finalidad. 
Figura 1.10

Fotografía de Evelyn Bencicova
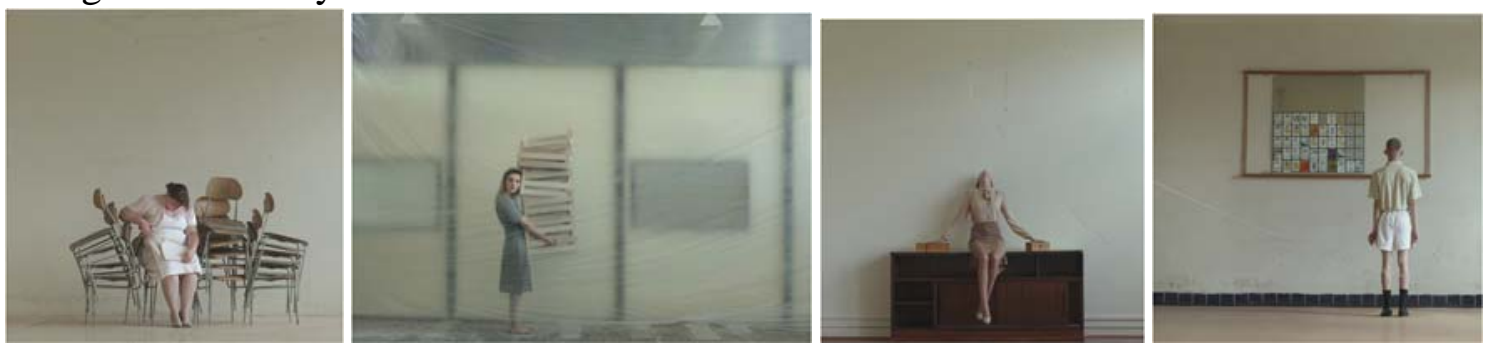

Fuente: Bencicova (2017)

11. Matt Lambert- “Keim/Vitium”: Matt Lambert es un videógrafo y fotógrafo que explora, entre otras cosas, a la juventud LGBT de Berlín. A través de retratos y metiéndose en espacios íntimos retrata una realidad atmosférica única. La intimidad masculina (entendida como una gama de múltiples masculinidades) es protagonista de su trabajo. Lambert trabaja mucho la idea de la cercanía entre el fotógrafo y modelo mezclando el tema de la identidad con intimidad. Su obra combina a la perfección el trabajo artístico que coexiste con un espíritu documental. Matt Lambert trabaja con mayor intensidad el claroscuro para realzar el carácter agresivo del contenido (Kane, 2016). La sesión realizada con Sebastián Ortiz de Zevallos, para alcanzar una intencionalidad más cruda, combina luz dura con un tratamiento más explícito y gestual.

Figura 1.11

Fotografía retrato de Matt Lambert
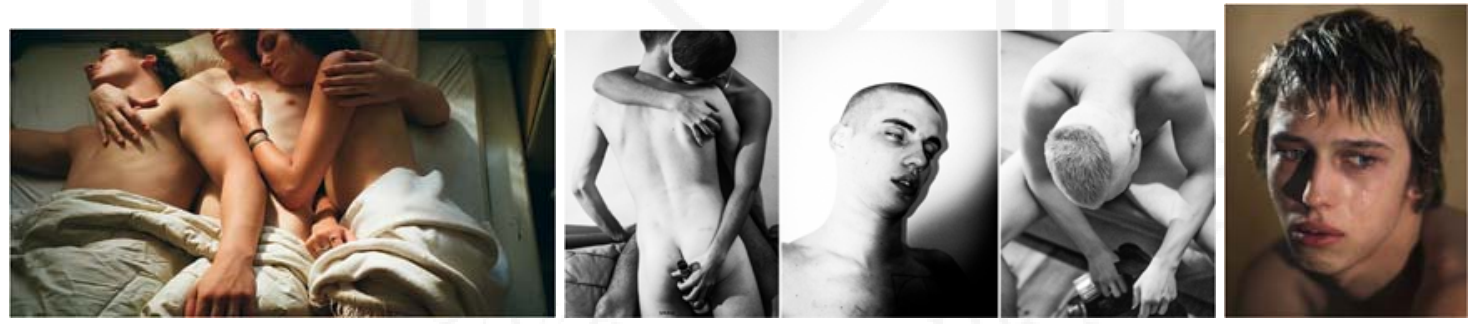

Fuente: Lambert (2019)

12. Ren Hang, “My Depression”: Ren Hang es un fotógrafo que se caracterizó por tomarle fotos a sus amigos en escenarios contradictorios. Fue un ícono por luchar contra la depresión y abordar la homofobia en un país tan conservador como China. Su fotografía explora el desnudo en relación al movimiento y la expresividad mezclando elementos cotidianos en contextos varios (Hang, 2017). Ren Hang, al igual que Látex en sus inicios, se remontaba a la experimentación con gente cercana. Cabe decir, sin embargo, que en el caso de Ren Hang estaba muy asociado a la transmisión de una sensación que evocaba la censura 
y la crudeza del contenido. Ren Hang rescata, sobre todas las cosas, la idea de que la autenticidad aparece una vez que uno se desprende de los estigmas sociales y los juicios de valor externos tal como se busca hacer en Látex.

Figura 1.12

Fotografías de serie My Depression de Ren Hang
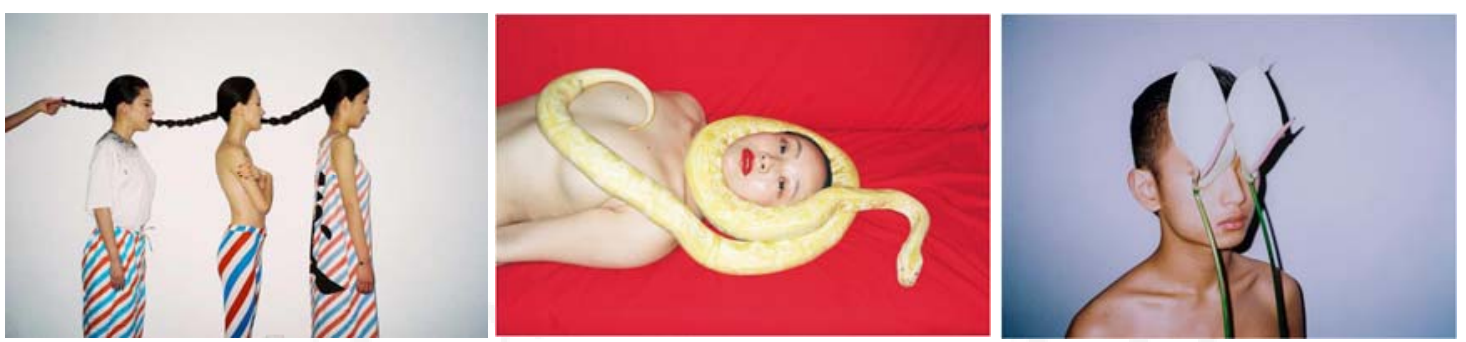

Fuente: Hang (2017)

13. Nan Goldin, fotógrafa americana nacida en 1953 es reconocida por su fotografía estilo snapshot o instantánea en la que retrata a la comunidad LGBTI y la subcultura de adictos a la heroína. Goldin es un antecedente clave en tanto su fotografía cuenta con una cuota documental y otra imaginaria. Goldin retrata usando generalmente un flash frontal que genera la sensación de inmediatez imaginaria, volatilidad y crudeza (Artnet, 2020). Esta fotógrafa fue mencionada en la entrevista con Estrada y ayuda a comprender, especialmente, la sesión realizada con Diego Perez Chirinos. En esta, se uilizó una cámara Fujifilm instantánea de 35mm con el fin de generar espacios, sensaciones y atmósferas similares a las de la fotógrafa.

Figura 1.13

Fotografia instantánea de Nan Goldin

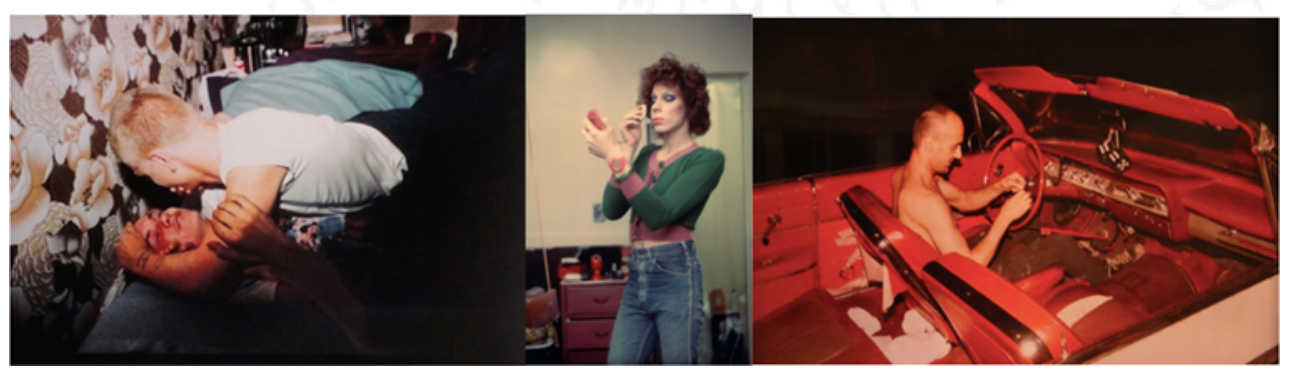

Fuente: Goldin (1973) 


\section{CAPÍTULO II: REALIZACIÓN O INTERVENCIÓN}

\subsection{Objetivo}

Objetivo General: Realizar una serie fotográfica en la que cada sesión se diferencie de la anterior en tanto esta represente la "esencia” de lo que el individuo quiera transmitir manteniendo una unidad general en la muestra.

Objetivos Específicos:

- Explorar patrones artísticos que desplieguen formas de representación del individuo por sesión.

- Construir un concepto de fotográfica colectiva de retrato sobre la identidad individual que tenga propiedades expandibles.

- Explorar y reflexionar sobre el rol de los fotografiados y la identidad construida del retratado en la serie fotográfica.

\subsection{Ejecución de sesiones}

La realización de las series de fotos se hacía tomando en cuenta que los valores técnicos (profundidad de campo, foco, luz) y expresivos (dirección de arte, composición, paleta de color) respondan a las condiciones de la misma sesión y al modelo en cuestión. Así, el entorno se incorpora al sujeto, que a su vez construye su universo. Como se ve en el cuadro de abajo, el proceso creativo involucraba un conocimiento básico del sujeto e intervención de este en cierta medida.

Estas fotografías responden a las primeras series realizadas a lo largo del 2016 para la primera exposición. A continuación, expongo algunos de los insights recogidos en las series y algunos de los criterios que fueron tomados en cuenta para su realización. 
Figura 2.1

Mosaico visual de primeros retratados por columna

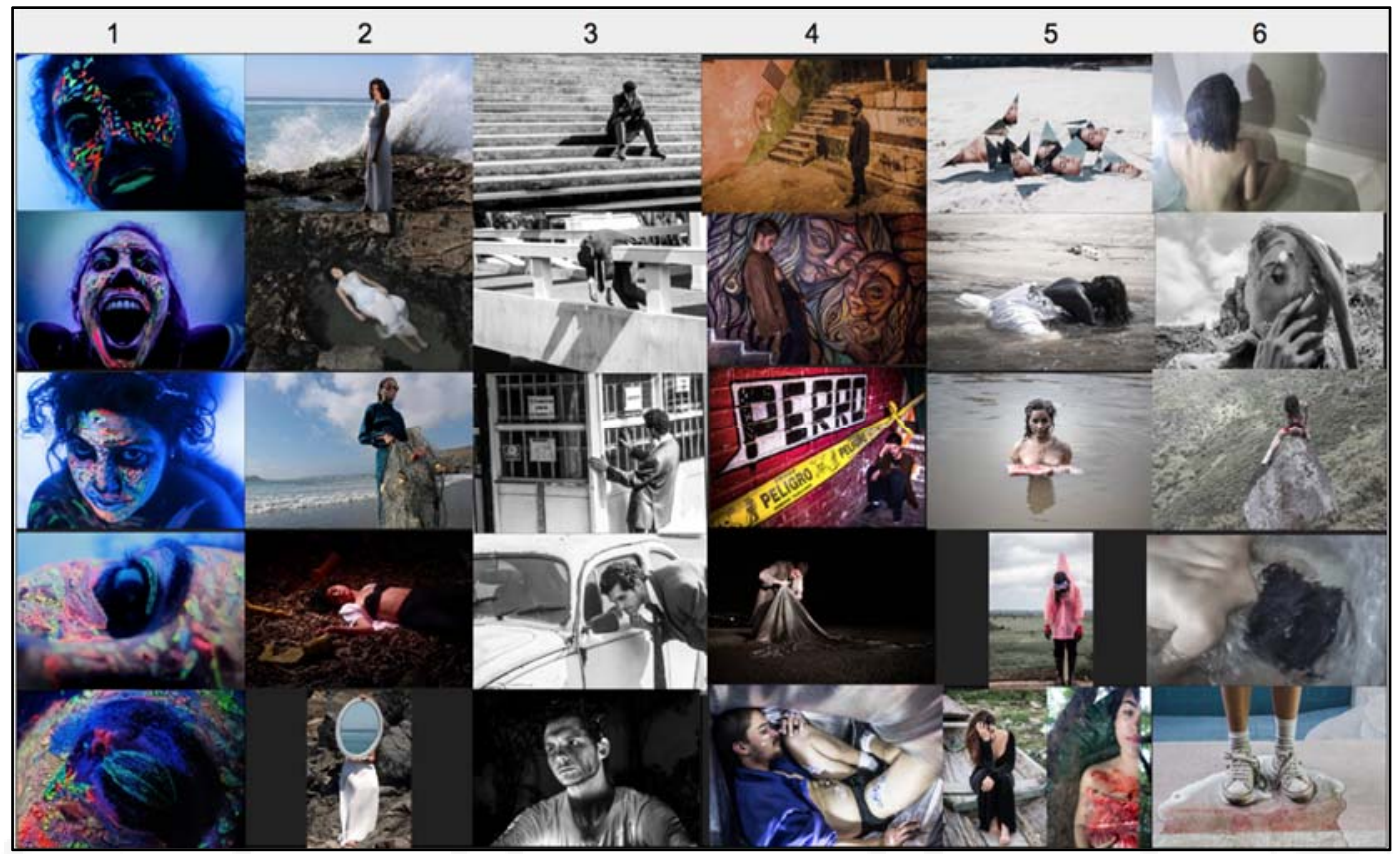

Elaboración propia

El mosaico mostrado se lee en columnas. Se muestra cómo cada retratado cuenta con un tratamiento visual, paleta de colores y dirección de arte general que se diferencia del resto. ${ }^{1}$

Figura 2.2

Fotografía de sesión realizada a Lorena Blume

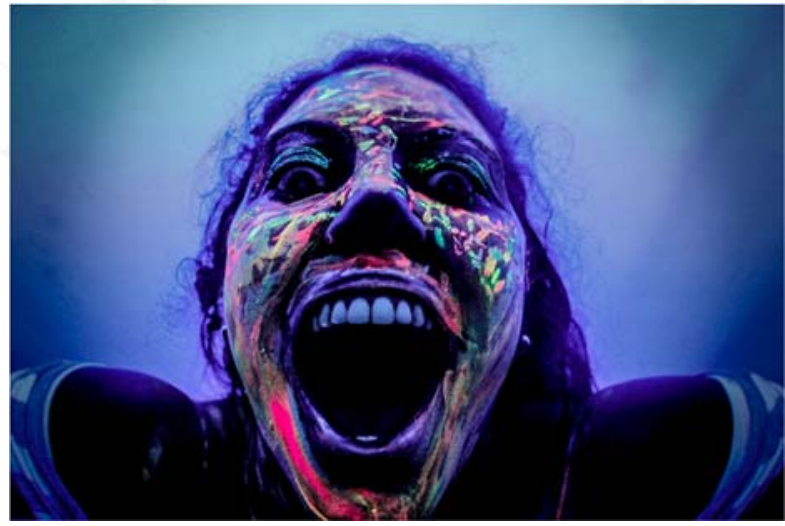

Elaboración propia

1 Para ver las fotografías expuestas en mejor calidad y antecedentes fotográficos entrar a este link: https://docs.google.com/presentation/d/1QVpfYLFnZpScMo9Tf8n2ow5GiGbTh2HbtQQ_X606yaw/edit?us $\mathrm{p}=$ sharing 
(1) La primera sesión fue realizada a Lorena Blume: con ella se buscó pensar en la posibilidad de expresar a través del arte lo que aparenta ser evidente, pero muestra cierto nivel de latencia: de ahí que la propuesta expresionista en color neón se manifieste a través de primeros planos con maquillaje y gestos exagerados. El discurso hace referencia al color que no se percibe hasta ser incidida por luz negra. Los planos detalles buscan entrar en la intimidad del sujeto a través de la paleta escogida y el orden de los elementos. La intimidad se construye a partir de primeros planos y planos detalle.

Figura 2.3

Fotografia de sesión realizada a Diana Chávez

Elaboración propia

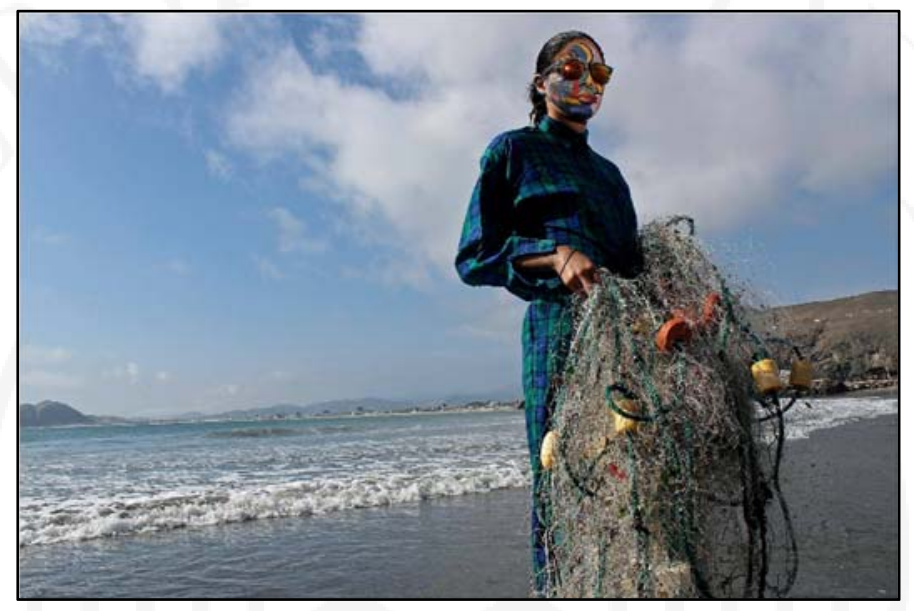

(2) La segunda sesión fue realizada a Diana Chávez de tal forma que coexistan entornos naturales fuera de contexto con elementos surrealistas que alteren el significado. Para esta sesión un referente clave es Alex Stoddard. La serenidad no es representada como algo intrínseco al sujeto sino a la composición en relación al entorno. El retratado se muestra calmo pero el arte responde de manera independiente a los estímulos externos buscando generar desconcierto en el espectador. Los elementos recurrentes hacían referencia al mar como símbolo de infinidad, es por eso que se opta por usar un diafragma cerrado para generar mayor profundidad. 
Figura 2.4

Fotografía de sesión realizada a Matías Campá

Elaboración propia

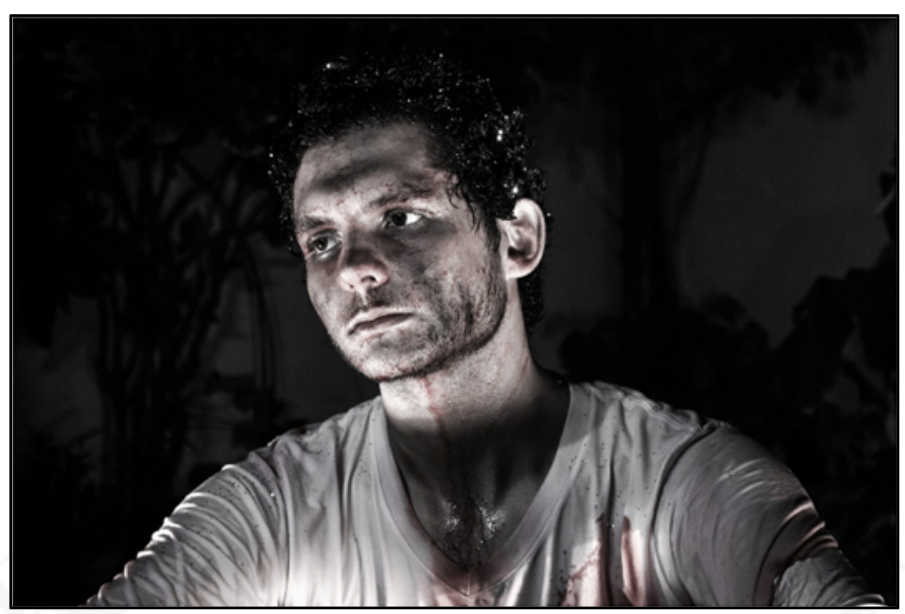

(3) Para la tercera sesión el sujeto fue Matías Campá. Él quería que se retrate su espíritu viejo y para llevar esto a cabo la sesión se hizo en la Residencial San Felipe. Fue importante, además, que las imágenes estuvieran en blanco y negro para reforzar esta idea de vejez y monotonía contrastada con la noción de violencia psicológica y salud mental. Se trabajan también temas como el agotamiento, la repetición y lo cíclico. Se optó adicionalmente por manchar la ropa del sujeto hacia el final de la sesión para denotar el paso del tiempo no solo desde la expresión sino desde el vestuario. Para esta serie es importante a su vez el uso de líneas y sombras. La fotografía final (Figura 2.4) tiene un rojo desaturado así como escarcha en el pelo para hacer puntos de luz. Si bien se usó una muestra de la serie en el 2017, para la exposición de 2019 se optó por incorporar otros colaboradores a retratar.

Figura 2.5

Fotografía de sesión realizada a Sebastían Ortiz de Zevallos

Elaboración propia

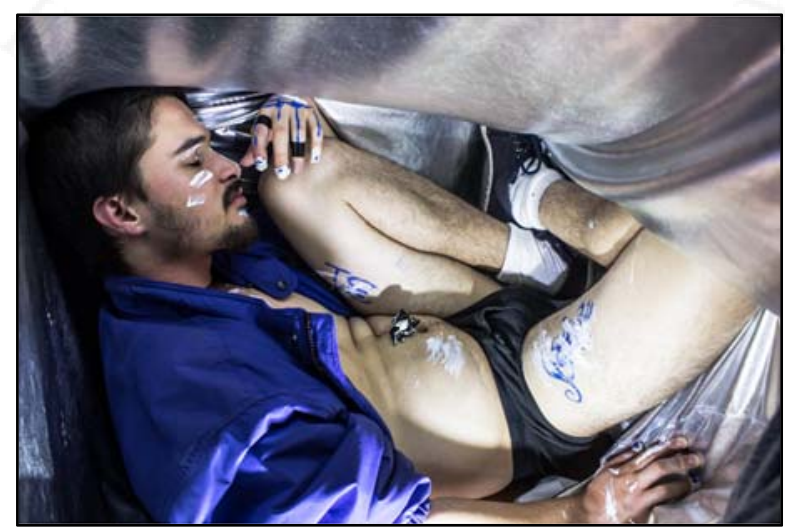


(4) La sesión de Sebastián Ortiz de Zevallos busca ser la más sórdida y cruda. El objetivo era mostrar la vulnerabilidad a través de la exposición. Para esto se utilizó una gran tela de látex como antagonista al sujeto retratado en relación al proyecto. Para el efecto agresivo se buscó que sea de noche para iluminar con flash, reducir la profundidad de campo y hacer énfasis en elementos específicos de la foto. Los colores utilizados transitan entre los colores tierra y el color azul brillante. Se hace énfasis compositivo en temas como la maternidad y la pérdida. Esta serie no tiene ejemplares en ninguna de las exposiciones por su naturaleza íntima y personal.

Figura 2.6

Fotografía de sesión realizada a Sofía Caravedo

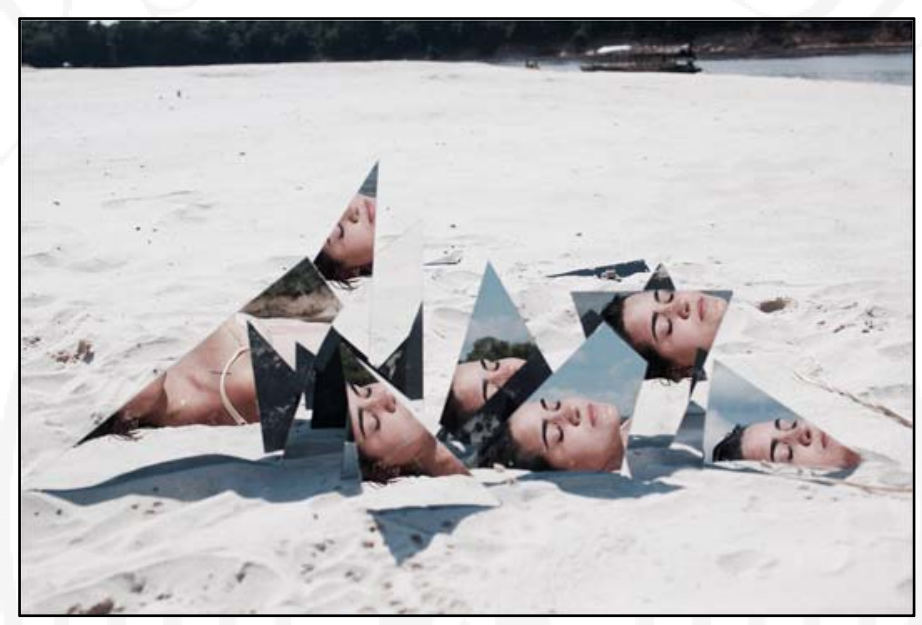

Elaboración propia

(5) La sesión de Sofía Caravedo se realizó en Iquitos. Esta sesión trataba de romper con los esquemas de la comodidad: trataba de reflexionar acerca de la importancia de estar cómodos con lo que tenemos y somos. De esta manera se utiliza la carne, la pintura negra y los espejos como metáforas de la esencia de un entorno natural simulado que busca reivindicar sus demonios internos a través de la proyección. El arte contempla el uso de elementos industriales como enterizos de construcción y un impermeable en contraste con una prenda formal. Como bien diría Susan Sontag (2015): “La fotografía es el paradigma de una relación inherentemente equívoca entre el yo y el mundo, y su versión de la ideología del realismo a veces dictamina que ese yo se anule a sí mismo frente al mundo, y a veces autoriza una relación agresiva con el mundo para celebrar el yo” (p.123). Para esta sesión se usaron como referentes visuales a Evelyn Bencicova (la idea de esconder al sujeto para exponerlo) y a Ryan James Caruthers en la manera de vincular la ilación narrativa. 
Figura 2.7

Fotografía de sesión realizada a Camila Varela

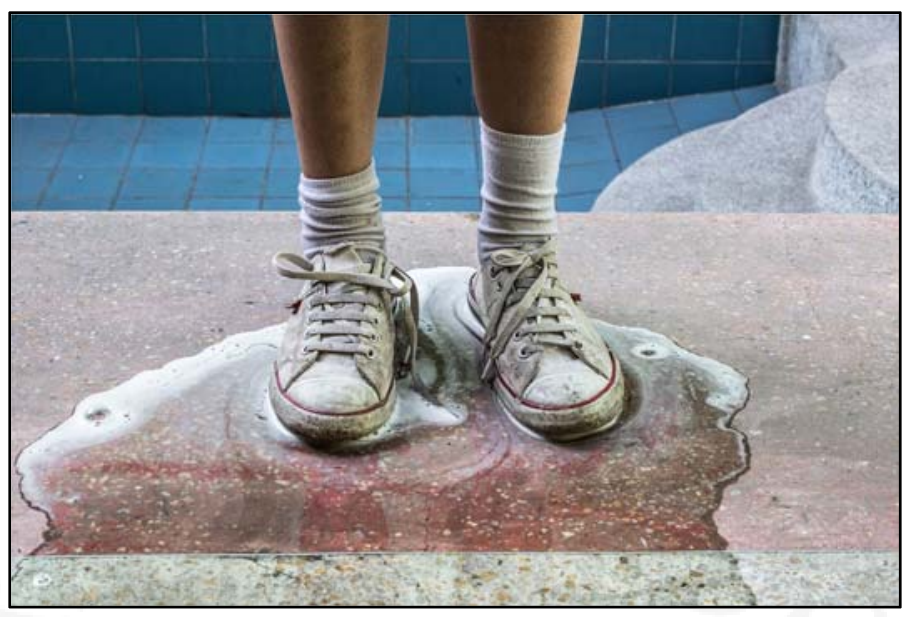

Elaboración propia

(6) Finalmente en la sesión de Camila Varela se exploró la idea de la adicción y la inocencia. La cerveza derramada bajo los pies y la cara cubierta fumando un cigarro son también metáforas que hacen referencia a un estilo de vida agresivo que contrasta con una serenidad y sensibilidad apabullante. En esta serie, además, vemos al retratado sumergiéndose y dándole la espalda al espectador en un acto nihilista que se resiste a contemplar la belleza natural. Por eso es que, en esta sesión, a diferencia de las anteriores, el sujeto se esconde y jamás muestra la cara. La sesión se hizo en su casa y en las lomas de Lúcumo. Se exploraron diferentes velocidades, profundidades y valores de plano según la fotografía que componía la serie y su intencionalidad.

Posteriormente, para la mejora y metodología más clara de la exposición del 2019 se incorporó un breve cuestionario sobre la identidad del sujeto para tener una mayor comprensión de este. Las preguntas fueron ¿Quién soy?, ¿Cómo hago lo que hago?, ¿Qué quiero mostrar?, ¿Qué quiero decir? ¿Qué me inspira?, ¿Qué escondo? y ¿Qué quiero hacer sentir? De acuerdo a estas respuestas se realizaron seis sesiones adicionales con Laia Ruiz de Eguilaz, Carolina Anaya, Camila Guerrero, Laura Alegre, Diego Perez Chirinos, Sebastían Palacios y Danelle Larrabure. Estas sesiones, buscaban seguir perpetuando la búsqueda por la representación de una identidad única desde la técnica y la expresión en cada persona. 
Figura 2.8

Mosaico visual de extensión fotográfica por columna

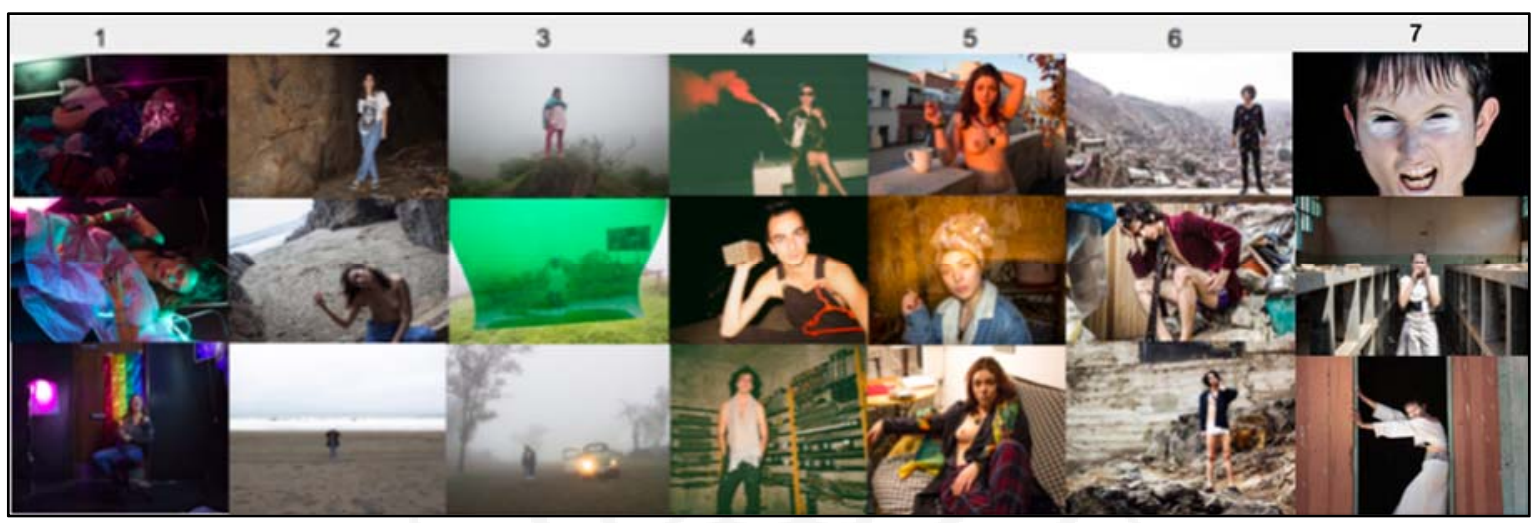

Elaboración propia

El mosaico mostrado se lee en columnas al igual que en el previo. Se muestra el mismo ejercicio por fotografiado y las diferenciaciones correspondientes con los sujetos adicionados para la muestra de 2019.

Para la perpetuación y extensión del proyecto se probó utilizando elementos del entorno del sujeto que permitan darlo a conocer más. Así, por ejemplo, la sesión de Diego Pérez (cuarta columna) se hizo haciendo uso de una cámara análoga para hacer alusión al pasado del sujeto construido para la serie. Cada modelo, también hacía alusión a un color que se buscaba fuera recurrente a lo largo de la sesión.

Una vez completadas las sesiones, el proceso de selección y edición se hacía en base a las asociaciones subjetivas que cada modelo encontraba en la conversación previa a la ejecución. Se buscó que exista un hilo conceptual adicional a la restricción estética del proyecto con la finalidad de que haya una interconexión que trascienda al campo visual. Sobre los últimos retratados, sus respuestas, propuestas y ejecución de las sesiones adjunto las siguientes descripciones: 
Figura 2.9

Fotografía de sesión realizada a Laia Ruiz Eguilaz

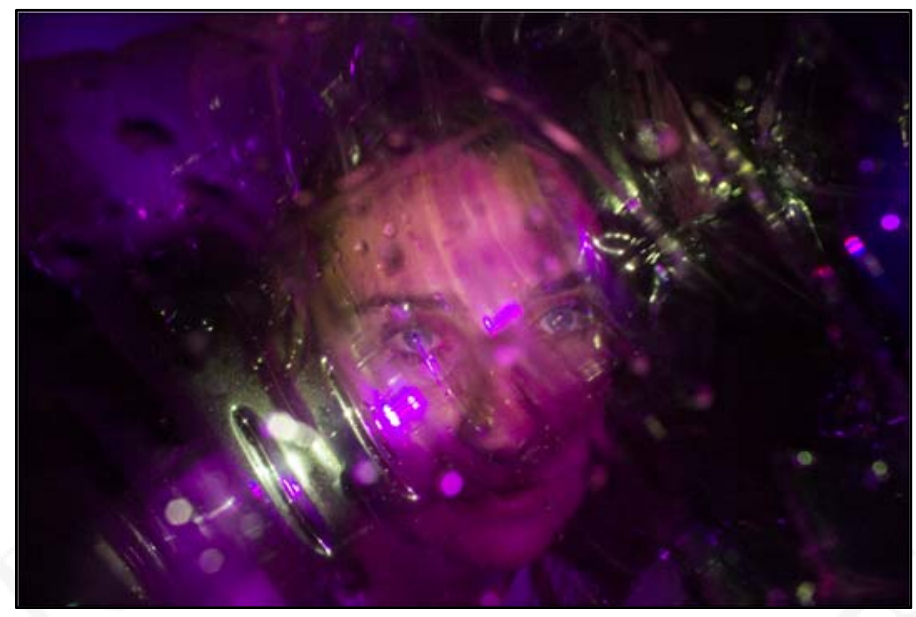

Elaboración propia

(1) Laia Ruiz de Eguilaz: Laia compartió su frustración frente a la falta de motivación y la recurrente sensación de estar encerrada. Adicionalmente, quería reflexionar alrededor de las mujeres luchadoras a las que admira y el respeto, confianza y amor que le transmiten. Para esto, se decidió tratar con colores tradicionalmente asociados a la feminidad, utilizando texturas sedosas y plásticas que denoten delicadeza y también fuerza. Para representar la sensación de encierro se optó por no usar exteriores y reforzar el discurso mostrando diegéticamente las fuentes de iluminación con las que se realizaron las sesiones correspondientes. Desde la fotografía, se probó usando interferencias en cámara para que la fuerza del retratado de concentre en la mirada. Si bien esta sesión sirvió como ejercicio, no se optó por seleccionar una fotografía para la muestra final sino para su difusión en redes.

Figura 2.10

Fotografía de sesión realizada a Carolina Anaya

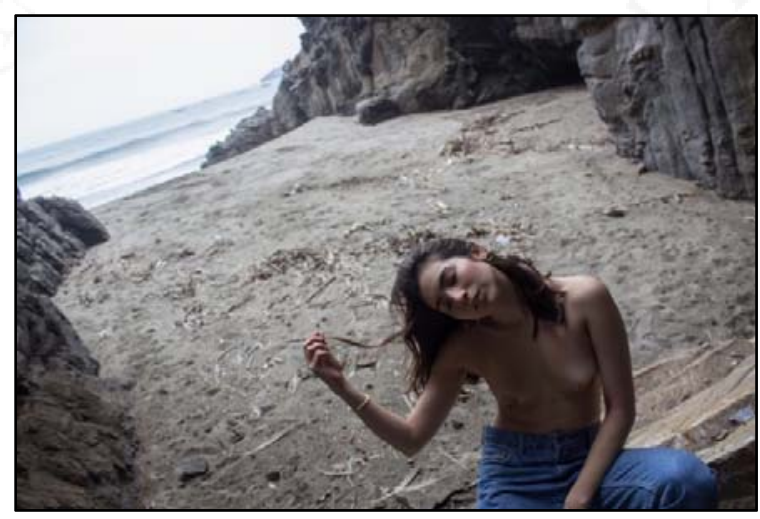

Elaboración propia 
(2) Carolina Anaya: Carolina quería mostrar su cuerpo en un entorno natural para cuestionar los estigmas que la acompañan. Se optó por usar colores terrosos y por jugar con la mimetización del mar y las cuevas como figura retórica. Se utilizó luz dura en los entornos naturales más oscuros, y contraluz en los espacios que lo propiciaban para generar una dualidad fácilmente identificable en la cuarta fila de la exposición del 2019. Así mismo, se buscó que las cuevas que conforman el entorno primario en la serie sirvan como elemento para hacer alusión a la naturalidad del cuerpo en mímesis con el espacio al descubierto.

\section{Figura 2.11}

Fotografía de sesión realizada a Camila Guerrero

Elaboración propia

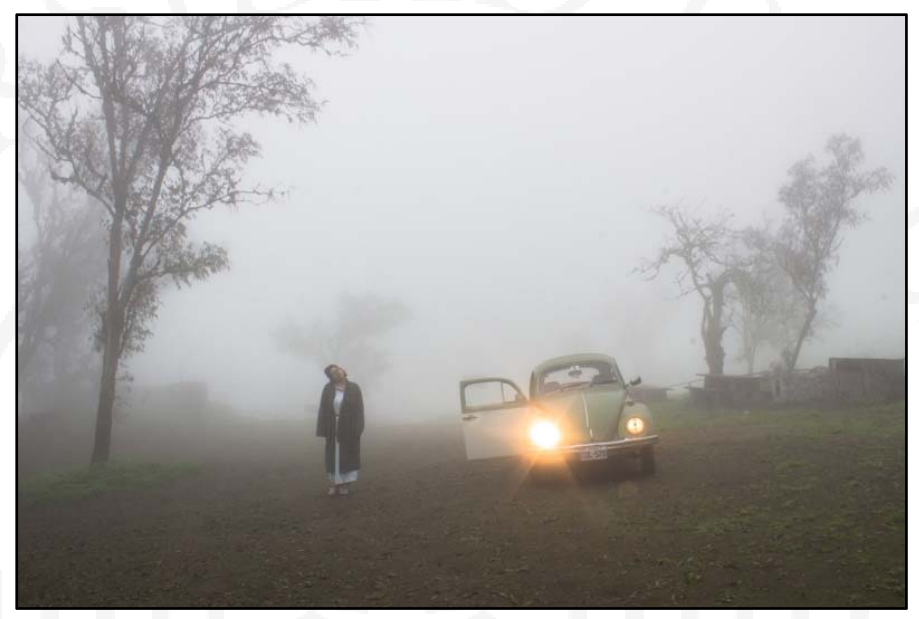

(3) Camila Guerrero: Camila quería dirigir su discurso hacia la depresión y la imposibilidad de ver la realidad tal como es. Se decidió en conjunto visitar las Lomas de Lachay para utilizar la neblina como principal figura retórica y el color verde como medio para representarlo. Se buscó incorporar elementos de su entorno natural para caracterizar al personaje construido. Para la ejecución de la sesión se usaron filtros de color como metáfora de la imposibilidad que se tiene para contemplar la realidad en su tonalidad original. 
Figura 2.12

Fotografía de sesión realizada a Diego Pérez Chirinos

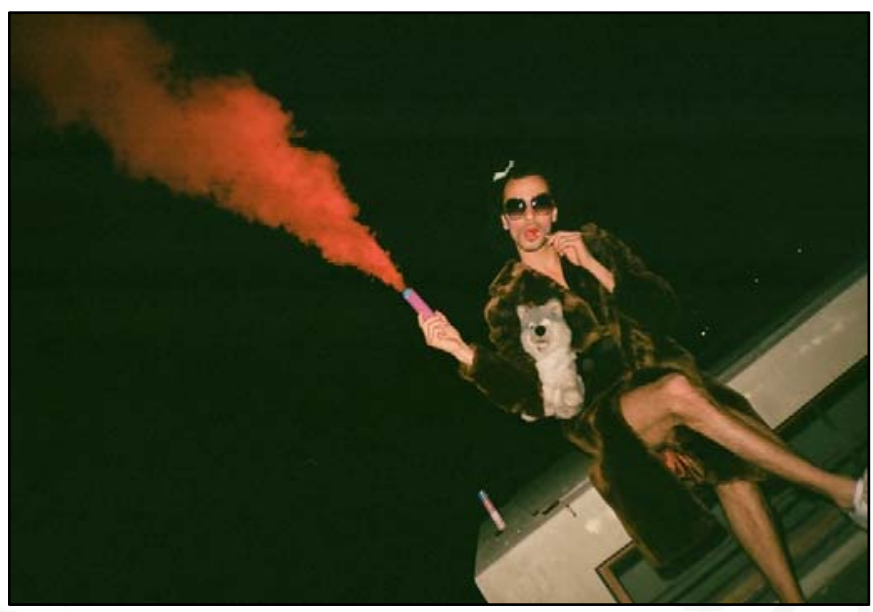

Elaboración propia

(4) Diego Perez Chirinos: La serie de Diego es la que más piezas individuales exhibe en la muestra de 2019. Al ser actor, se tomó la decisión de armar personajes que aludan a distintos aspectos de su personalidad que teme o le incomodan y que aluden a su pasado. Para la realización de esta, se utilizó una cámara de rollo análoga con la intención de denotar que los personajes en cuestión pertenecen a otro periodo distópico. Se utilizaron elementos de su entorno, tal como sucede con todos los retratados que, a medida que se construía la serie, iban tomando matices más surreales y expresionistas que contrastaban con la naturalidad original. Esto, con el fin de desarrollar con mayor intensidad las características artificiales.

Figura 2.13

Fotografía de sesión realizada a Laura Alegre

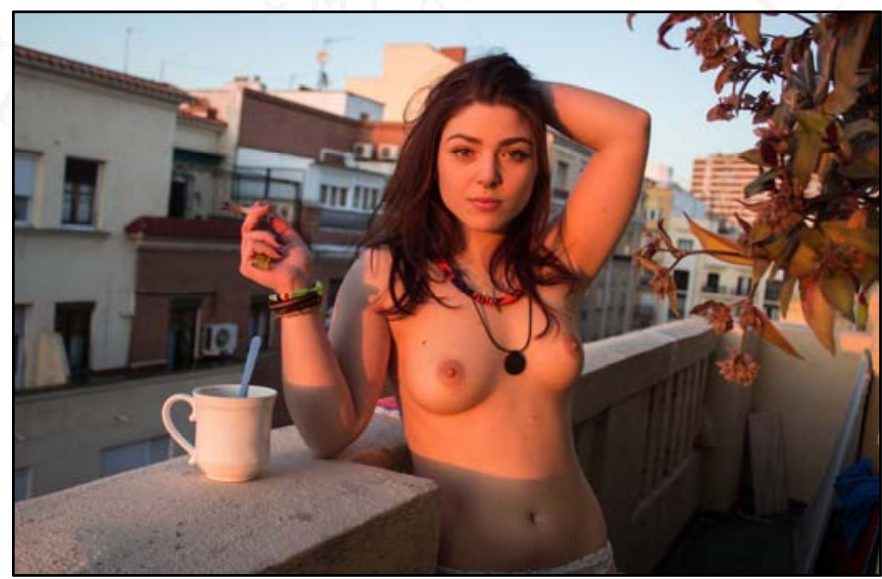

(5) Laura Alegre: Para Laura se buscó retratar la libertad con la que vive su vida. Ella pidió especialmente salir topless y ponerse pañuelos en la cabeza. Se mezclan planos 
generales y busto para combinar su entorno con sus expresiones. Hay juegos de luz con la tela para distanciar al espectador del sujeto y claroscuros para ocultar partes del cuerpo y que no toda la imagen quede igualmente expuesta. El tratamiento de la serie se da desde la naturalidad y para esto se buscó desde el arte descartar todo elemento que no sea documental. Dada la naturaleza más gráfica de esta serie, tampoco muestra piezas en la exhibición.

Figura 2.14

Fotografía de sesión realizada a Sebastián Palacios

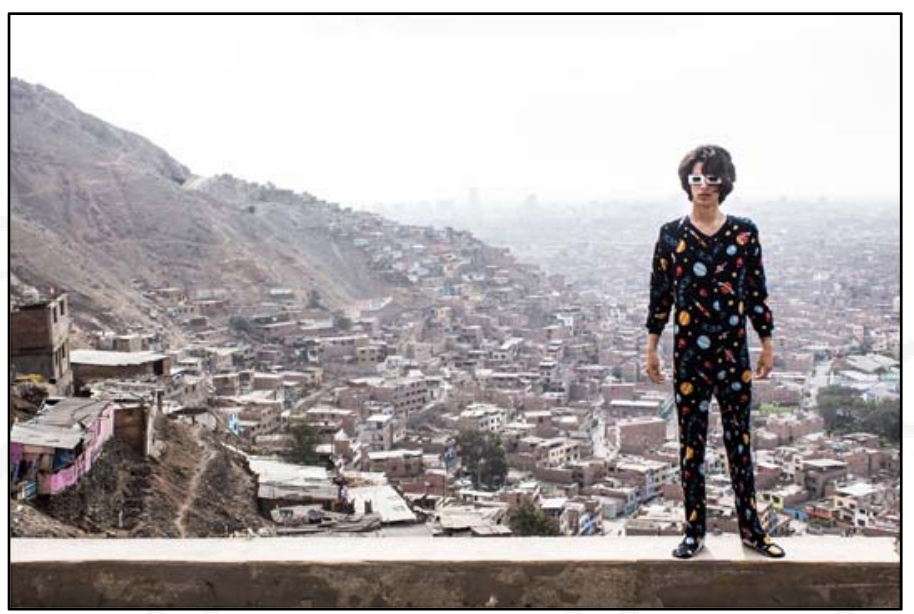

Elaboración propia

(6) Sebastían Palacios: El caso de Sebastián Palacios es, quizás, el más interesante desde el discurso. Sebastián, de los trece retratados, es el único que ejerce como modelo profesionalmente. Se quiso así, asociar la sesión, no a su profesión, sino más bien a lo que se quería representar. Se cuestiona el rol del modelo desde la disposición del espacio generando así un sujeto que no se acopla a su entorno y se resiste a hacer mímesis. Así, en lugar de realizar la sesión en un espacio que propicie un resultado más armónico, las fotografías se tomaron en Puente Piedra con la finalidad de generar mayor contraste. El vestuario utilizado, además, buscaba ser estrambótico para estar alineado a la personalidad de Sebastián. Así, la serie representa los contrastes característicos del entorno que retrata. 
Figura 2.15

Fotografía de sesión realizada a Danelle Larrabure

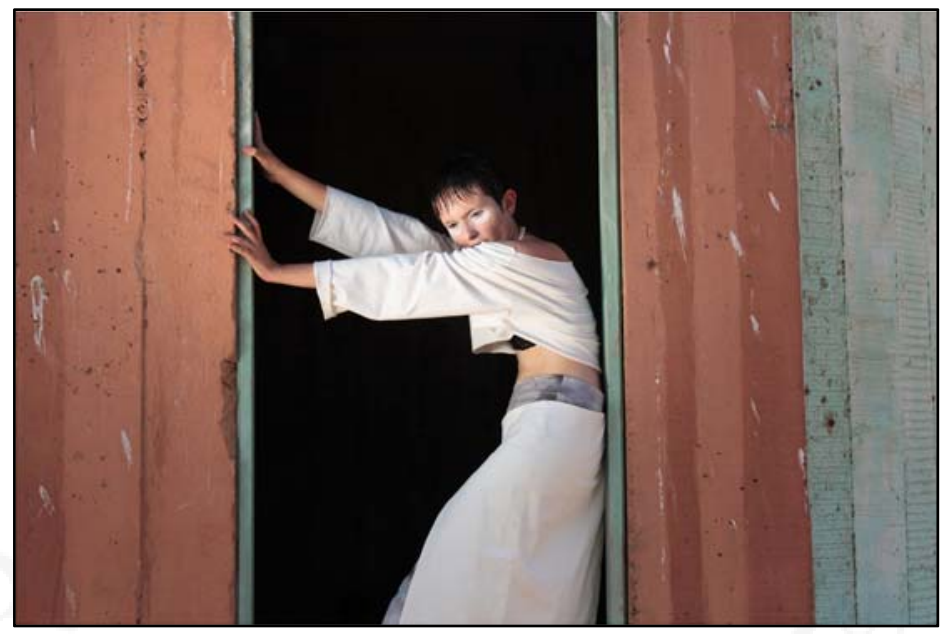

Elaboración propia

(7) Danelle Larrabure: La sesión realizada a Danelle Larrabure presenta la fotografía mostrada previamente en la exposición de 2019. La serie de Danelle fue tomada en una fábrica abandonada de Pucusana. Desde el styling, se optó por poner gel en el pelo para separar en pequeños mechones el pelo del cerquillo. Adicionalmente, se agregaron sombras blancas debajo de los ojos. El vestuario de Danelle, a diferencia de las demás series donde se trabajó con los elementos disponibles y propuestos por los sujetos, el vestuario fue diseñado y confeccionado por Chiara Parodi, quien realizó una serie basada en las camisas de fuerza usadas en manicomios. La serie hace referencia a la salud mental con un tratamiento gestual exagerado que presenta al sujeto siempre centrado en el encuadre. 


\section{CAPÍTULO III: SUSTENTACIÓN}

\subsection{Justificación del proyecto}

El objetivo es aportar con una nueva modalidad de fotografía en la que se diversifique el contenido. De esta manera, encontramos múltiples plataformas de acceso a este: en primer lugar, tenemos la posibilidad de expansión por cuota de uso. Esta modalidad contempla la posibilidad de acceder a Galerías de arte, figurar en revistas de fotografía por suscripción o conseguir auspicios. También, tomando en cuenta las características del público, se podrían evaluar mecanismos de crowdfunding para la continuación del proyecto.

Las cualidades innovadoras de la propuesta se sustentan en la idea de que el modelo es ahora un participante activo y no solo un sujeto a retratar. Para la realización de cada serie es fundamental que se converse con el modelo previamente acerca de lo que él o ella tienen que decir y quieren expresar. El objetivo final es que la diferenciación entre las sesiones se dé de manera natural al diferenciarse no por una búsqueda del fotógrafo sino como fenómeno natural de la representación individual del retratado. En ese sentido es importante que la locación responda a las características de la persona retratada con la finalidad de caracterizarla y convertirla en un personaje representativo de él mismo.

Si hacemos un paralelismo entre el rol del modelo publicitario (Mejía, 2016) y el modelo en la fotografía de moda a lo largo del tiempo (Oviedo, 2000) podemos identificar que inicialmente el modelo era un prop o tan solo el encargado de ser portador de la ropa (en el caso de la moda). En los años 80, con el surgimiento de los supermodelos, se restablece la importancia de estos, sin embargo, con este viene también el estigma y los estándares de belleza que impone la sociedad. Tanto los hombres como las mujeres, especialmente ahora con la llegada de la publicidad, son depositarios de símbolos que refuerzan estereotipos y roles de género. Látex busca, en ese sentido, devolverle al modelo la importancia que tuvo cuando empezó la fotografía de retrato y el modelo tenía mayor acceso a la dirección de arte.

Como beneficiarios tenemos tres partes: en primer lugar, el fotógrafo, que al ayudar a representar de manera conjunta el espíritu humano logra agregar un valor simbólico. En segundo lugar, tenemos al modelo que, al no ser profesional necesariamente, puede probar algo nuevo exponiéndose a descubrirse en el ámbito visual. Finalmente, tenemos a los consumidores finales que pueden proyectar sus propias inquietudes en el producto final. 
Como se ve en el siguiente cuadro comparativo por sesión, se buscó identificar elementos diferenciales por retratado con el fin de perpetuar una búsqueda diferenciada por fotografiado. Para esto se separaron aspectos tal como las características relacionadas a aspectos puntuales tanto de la técnica fotográfica, como del arte en cuestión por representado. Dada la naturaleza colectiva del proyecto se optó por considerar al fotografiado como un personaje en construcción y artificio comunicacional de su propio discurso. 
Tabla 3.1

Relación de factores alterados por sesión fotográfica realizada

Fuente: Elaboración propia

\begin{tabular}{|c|c|c|c|c|c|c|c|c|}
\hline Sujeto & Maquillaje /Peinado & Vestuario & Espacio & Color & $\begin{array}{l}\text { Valor } \\
\text { Plano }\end{array}$ & $\begin{array}{l}\text { Velocidad } \\
\text { Promedio }\end{array}$ & $\begin{array}{c}\text { Profundi } \\
\text { dad }\end{array}$ & $\begin{array}{c}\text { Símbolos / Figuras } \\
\text { Retóricas }\end{array}$ \\
\hline $\begin{array}{l}\text { Lorena } \\
\text { Blume }\end{array}$ & Pintura Expresionista & Desnudo & Estudio & Neones & Cerrado & $60 \mathrm{fps}$ & Mínima & Pintura Neón \\
\hline $\begin{array}{l}\text { Diana } \\
\text { Chavez }\end{array}$ & Abstracto / Andrógino & Surrealismo & Playa & Primarios y verde & Abierto & $300 \mathrm{fps}$ & Máxima & Mar \\
\hline $\begin{array}{l}\text { Matias } \\
\text { Campa }\end{array}$ & $\begin{array}{c}\text { Transición de Orden a } \\
\text { Desorden }\end{array}$ & Formal & $\begin{array}{l}\text { Residencial San } \\
\text { Felipe }\end{array}$ & $\begin{array}{c}\text { Blanco y Negro + Rojo } \\
\text { Desaturado }\end{array}$ & Entero & $60 \mathrm{fps}$ & Media & Líneas / Manchas \\
\hline $\begin{array}{l}\text { Sebastian } \\
\text { Ortiz }\end{array}$ & $\begin{array}{c}\text { Pintura blanca en } \\
\text { detalles }\end{array}$ & Desnudo & Barranco & Tierra + Azul & Abrierto & $10 \mathrm{sec}$ & $\begin{array}{l}\text { Media - } \\
\text { Baja }\end{array}$ & Látex \\
\hline $\begin{array}{c}\text { Sofia } \\
\text { Caravedo }\end{array}$ & Pintura negra / Sangre & $\begin{array}{l}\text { Industrial / } \\
\text { Formal }\end{array}$ & Iquitos & Tierra + Verde & Variable & $100 \mathrm{fps}$ & Alta & $\begin{array}{c}\text { Espejos / Sangre / } \\
\text { Selva }\end{array}$ \\
\hline $\begin{array}{l}\text { Camila } \\
\text { Varela }\end{array}$ & Natural & $\begin{array}{l}\text { Propio / } \\
\text { Desnudo }\end{array}$ & $\begin{array}{c}\text { Baño + Lomas de } \\
\text { Lúcumo }\end{array}$ & Natural Desaturado & Variable & $30 \mathrm{fps}$ & Media & Cerveza / Cigarro \\
\hline Laia Ruiz & Natural & Propio & Cuarto (Propio) & Morados & Abierto & $80 \mathrm{fps}$ & Baja & Plástico / Tiras Led \\
\hline $\begin{array}{l}\text { Carolina } \\
\text { Anaya }\end{array}$ & Beauty Natural & Jean /Desnudo & Cuevas - playa & Marrón + Blanco + Azul & Entero & $60 \mathrm{fps}$ & Alta & Cuevas \\
\hline $\begin{array}{l}\text { Camila } \\
\text { Guerrero }\end{array}$ & Natural & $\begin{array}{l}\text { Propio } \\
\text { Intervenido }\end{array}$ & Lomas de Lúcumo & Verde & Abierto & $60 \mathrm{fps}$ & Media & Neblina / Filtros \\
\hline Diego Perez & Desorden Progresivo & $\begin{array}{c}\text { Desorden } \\
\text { Progresivo }\end{array}$ & Azoteas & Negro y Rojo & Abierto & $200 \mathrm{fps}$ & Media & Soporte Analógico \\
\hline $\begin{array}{l}\text { Laura } \\
\text { Alegre }\end{array}$ & Natural & $\begin{array}{l}\text { Propio / } \\
\text { Desnudo }\end{array}$ & $\begin{array}{l}\text { Madrid - } \\
\text { Argüelles }\end{array}$ & Crema & Entero & Variable & Alta & Pañuelos \\
\hline $\begin{array}{c}\text { Sebastian } \\
\text { Palacios }\end{array}$ & Natural & $\begin{array}{l}\text { Distópico / } \\
\text { Aleatorio }\end{array}$ & Puente Piedra & Concreto & Abierto & $120 \mathrm{fps}$ & Alta & Lentes 3D / Enterizo \\
\hline $\begin{array}{c}\text { Danelle } \\
\text { Larrabure }\end{array}$ & $\begin{array}{c}\text { Gel y Maquillaje } \\
\text { Blanco }\end{array}$ & Chiara Parodi & Pucusana & Blanco & Variable & $60 \mathrm{fps}$ & Media & Concreto \\
\hline
\end{tabular}


Se busca que idealmente cada representado se aísle desde el tratamiento formal y desde el uso de una simbología propia que responda a las necesidades y proyección de cada retratado. Un reto que constituye este proceso es la búsqueda activa por no reincidir en el uso de determinados elementos, tal como sucede con las paletas de colores seleccionadas por los mismos retratados. Se buscó, sin embargo, tomar en cuenta la unidad discursiva desde una narrativa compartida que se resuelva en el uso de un cuerpo en mímesis con un espacio construido y designado a él.

Si bien todos los retratados mantienen una distinción formal, dicha distinción está supeditada a la idea de que yace un discurso universal alrededor de la identidad colectiva que se devela. La búsqueda activa por un tratamiento diferencial se sustenta, así, en el ejercicio de diluir la mirada fotográfica en la medida que esta responde a valores pre asignados por retratado.

Con el fin de hilvanar la relevancia del proyecto en el arte contemporáneo se realizó una entrevista a Arístides Gonzales Vigil, miembro del comité consultivo de PArC Lima y director de la galería Vigil Gonzales. Cuando se le preguntó por la relevancia del contenido de la muestra, destacó que el arte contemporáneo se caracteriza por ser una conversación protagonizada por preguntas y repreguntas.

Desde la interrogante, el hecho de que cada sujeto tenga la libertad de participar en el proceso creativo y que cuente también con la posibilidad de escoger la forma de representar la artificialidad en su propia construcción, da pie a situaciones tanto literales como metafóricas que evocan la problemática de definir esta artificialidad. Así, la dicotomía existente entre lo contado y lo no-contado se enfoca en la exploración de la artificialidad en la vida cotidiana o realidad inmediata a partir de la multiplicidad de interpretaciones.

Gombrich afirma que "El arte sólo empieza a tener sentido cuando vemos qué no es arte, y también por qué pintores y escultores respondieron a situaciones distintas, instituciones y modas de modos muy diferentes” (2014, p.486). Los retratados de la serie, así, encuentran sus propias respuestas a las interrogantes según la composición de sus propias ideas y esquemas representativos creando cada uno de ellos una representación única de su propio artificio. 


\subsection{Exposición 2017}

Figura 3.1

Disposición de exposición de 2017

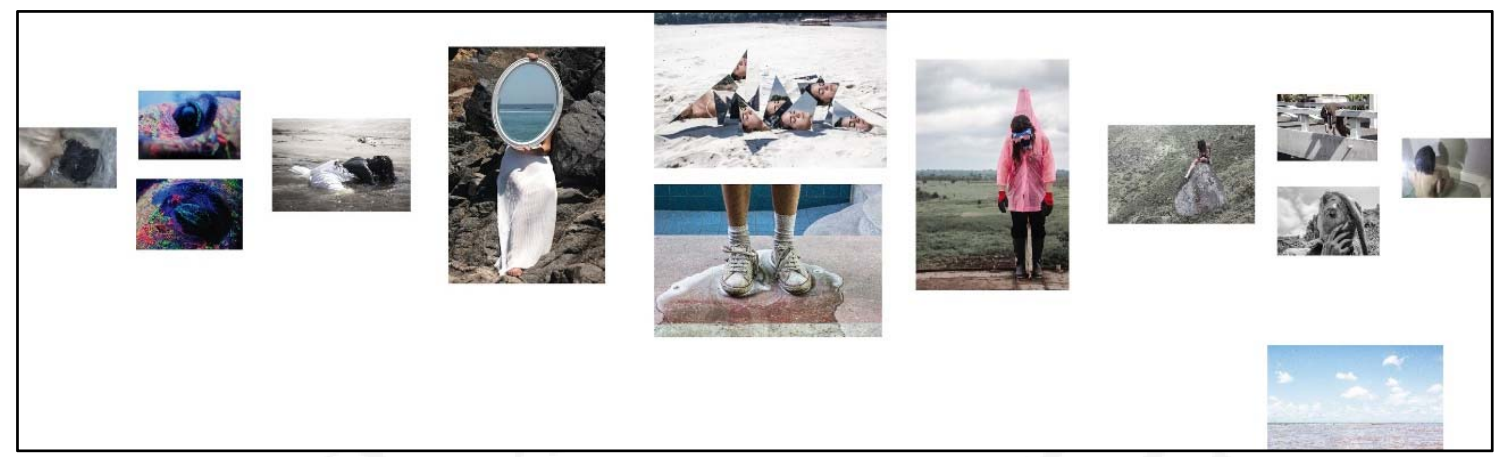

Elaboración propia

Arriba vemos la exposición del 2017: Para esta se toma la idea de una muestra personal que expanda el mundo de Látex en vez de restringirlo a sus propias limitaciones conceptuales. Tal como recomendó el docente José Guzmán al ser consultado, la muestra no expone todas las fotografías, sino que adopta la forma de una exposición personal dentro del marco conceptual propuesto por Látex. Si el visitante de la obra deseaba ver cada muestra independiente de Látex, tenía la posibilidad de ingresar a la página de Facebook (Ilan Valdés) donde están publicadas las muestras de acuerdo al grupo de la serie.

Se escogieron, entonces, las fotografías más representativas de cada serie con la intención de exponer al espectador a una experiencia antes que a un concepto. El objetivo era que se inmiscuya en la experiencia sensorial con la finalidad de que la muestra adquiera su propio significado sin que esté supeditada al concepto y adquiera un carácter propio. Para esta exposición se escogió terminar la serie con un paisaje con la finalidad de crear un universo ficcional en el que los sujetos pasen a un segundo plano y sean, si se quiere, reabsorbidos por su entorno natural.

La validación oficial se dio el 19 de enero del 2017 en una exposición conjunta con los fotógrafos Julián Estrada, Alonso la Hoz, Macarena Puelles y Rodolfo Arrascue. El evento fue realizado en el Club Regatas. El discurso detrás de la muestra buscaba condensar el recorrido fotográfico de los expositores de tal forma que, en un espacio de tres metros, se logre depositar un mensaje. La exposición tenía en la entrada una pantalla con videos en los que cada fotógrafo exponía el contenido de sus fotos. De esa manera, el público que asistía estaba informado con respecto al contenido y concepto de Látex antes de ver las fotografías. 
Con más de 400 asistentes confirmados en Facebook, dos auspiciadores, un performance y música en vivo de parte de dos grupos musicales, la inauguración fue un éxito. La muestra estuvo vigente por más de dos semanas en las que cualquier persona podía acceder haciendo uso de la invitación. Se realizaron, además, visitas guiadas para promocionar las muestras. 
Figura 3.2

Elementos de difusión del evento en el Club Regatas

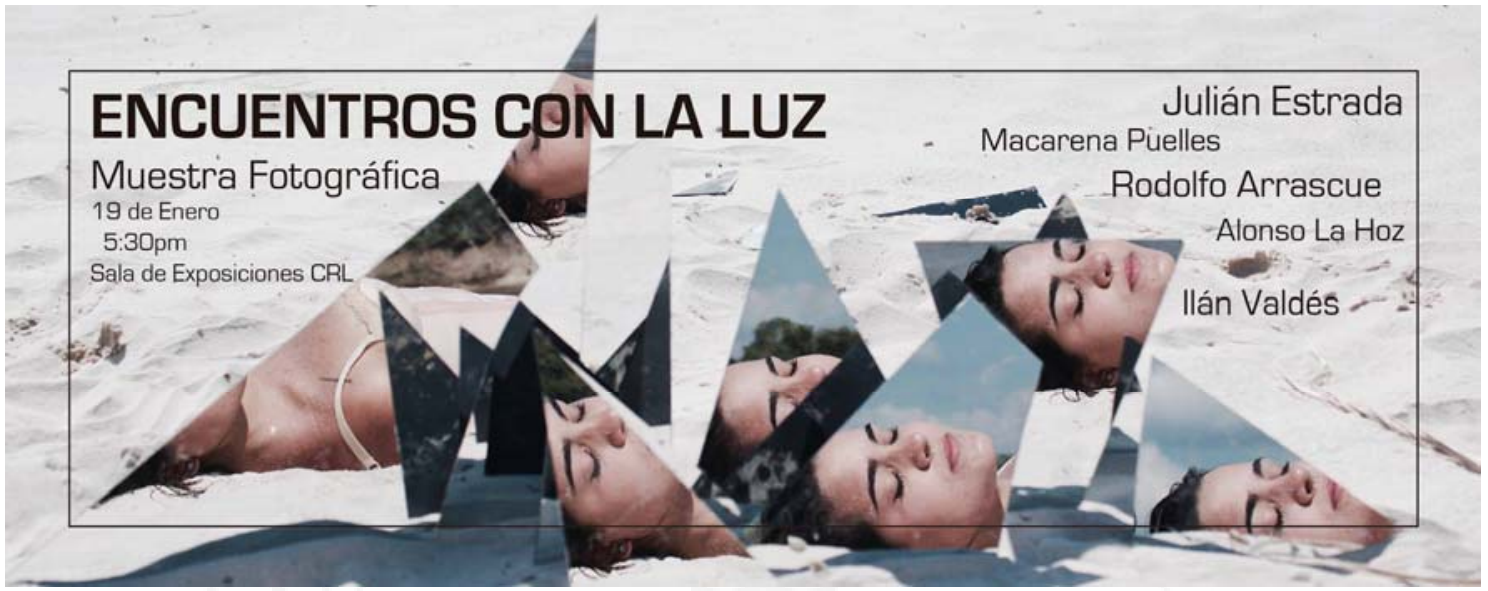

Exposición Colectiva de Fotografía

"ENCUENTROS CON LA LUZ"

Del jueves 19 de Enero al 12 de Febrero del 2017

LUGAR: Sala de exposiciones del Club de Regatas "Lima"

PRESENTACIÓN

6 fotógrafos jóvenes provenientes de importantes escuelas artísticas,

presentan diversas aproximaciones al acto fotográfico.

Paisajes, retratos, puestas en escena y experimentos conforman la gama

de posibilidades. Por medio del color, la composición y la textura ellos

nos comparten su forma de ser y sentir su entorno. Con diferentes

tratamientos estéticos, pero con

la misma pasión por la fotografía

ARTISTAS PARTICIPANTES

Alonso La Hoz

Julián Estrada

Rodolfo Arrascue

Macarena Puelles

\|lán Valdés

La inauguracion contará con una demostración experimental de fotografia a cargo del colectivo.

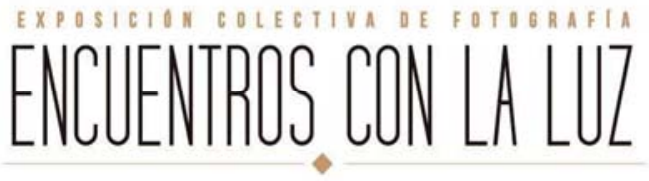

El Vicepresidente del Club de Regatas "Lima", tienen el agrado de invitar a usted y a su familia la Inauguración de la exposición colectiva: ENCUENTROS CON LA LUZ.

Jaime Crosby Robinson agradece su asistencia.

JUEVES 19

$7 \cdot 30$ P.M.

SALA DE EXPOSICIONES CULTURALES

Visitas: Lunes a Sábado de 11:00 a.m. a 8:00 p.m. / Domingo de 1:00 p.m. a 4:30

Telf.: 213-4567 / Anexo: 220 / E-mail: rcastro@clubregatas.org.pe

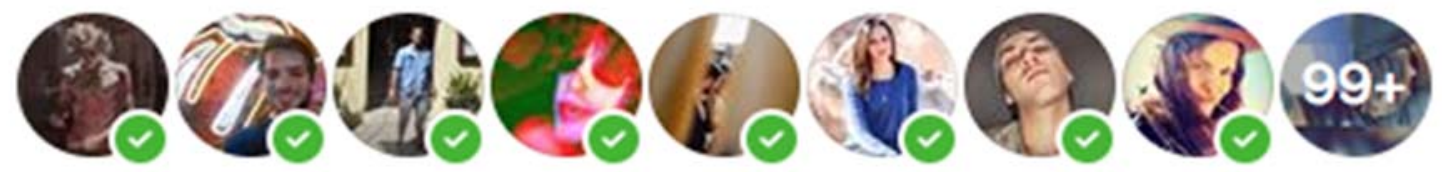

Patrick Guidn and 124 ather friends went

Elaboración propia 


\subsection{Exposición 2019}

Con la finalidad de extender el proyecto y mejorarlo, se realiza una extensión de la exposición gracias a la Universidad de Lima, quien permite volver a hacer la muestra con la incorporación de nuevos retratados para probar el objetivo con mayor rigurosidad. La exposición tuvo una duración de dos semanas desde el 14 de octubre y estuvo ubicada a lo largo del pasillo del segundo piso del pabellón E. Para esto se tomaron en cuenta dos posibles opciones de exposición que se discutieron posteriormente en la validación grupal.

Figura 3.3

Disposición inicial de exposición de 2019

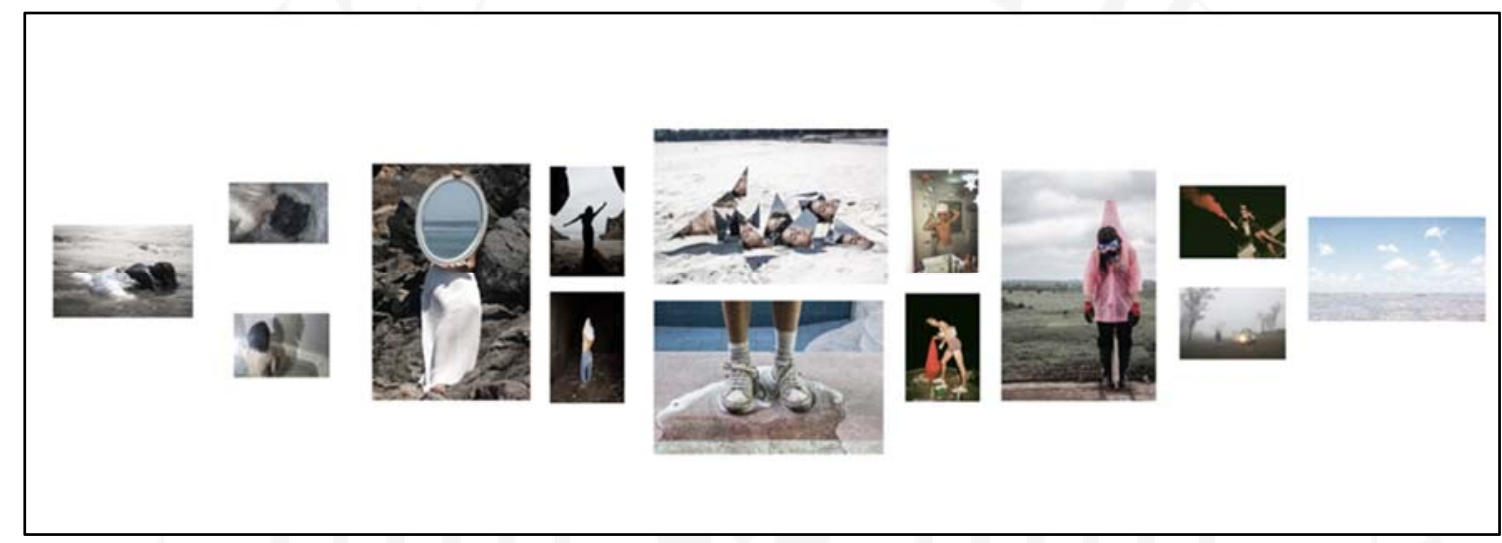

Elaboración propia

Cuando se realizó la primera maqueta de la exposición cabía la duda de si culminar la muestra (leyéndola de izquierda a derecha) con un paisaje o si, más bien, era conveniente abordar el discurso de la identidad como algo cíclico para su posterior entendimiento. Adicionalmente, a diferencia de la exposición del 2017, contaba con una doble entrada, lo que motivó a tener una disposición que propicie una lectura tanto de izquierda a derecha como al revés. Es así como se descartó el final con paisaje del 2017 y se propuso el siguiente esquema: 
Figura 3.4

Disposición final de exposición en 2019

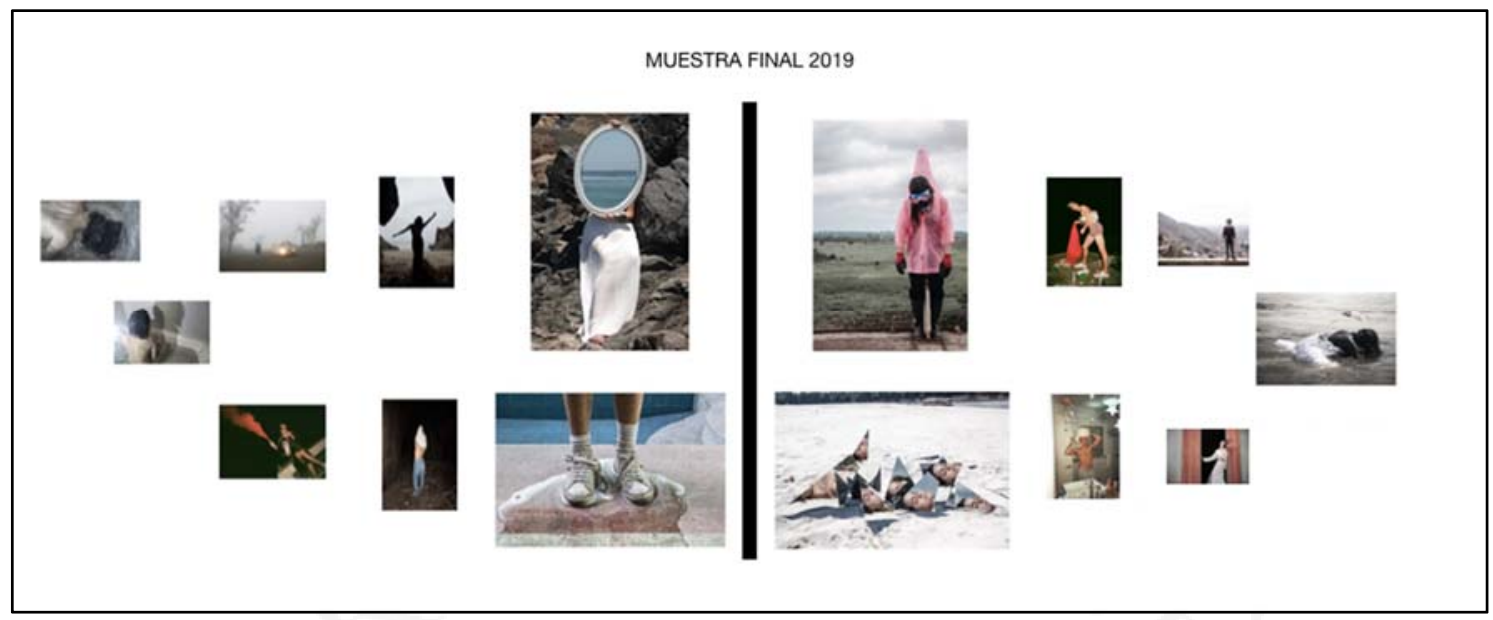

Elaboración propia

Esta fue la disposición final de la muestra. Se decide así escribir un breve texto curatorial que acompañó la serie y la dividió: “LÁTEX: Látex busca cuestionar el rol del modelo en la fotografía desde la construcción de series que se diferencien entre ellas. El acercamiento se hace a partir de un cuestionamiento sobre la identidad. Se retrata al otro desde el cuestionamiento y la experiencia compartida. Látex es un proyecto para exponerse, construir, sanar y re-conocerse.”

Figura 3.5

Vista bilateral de la exposición de 2019

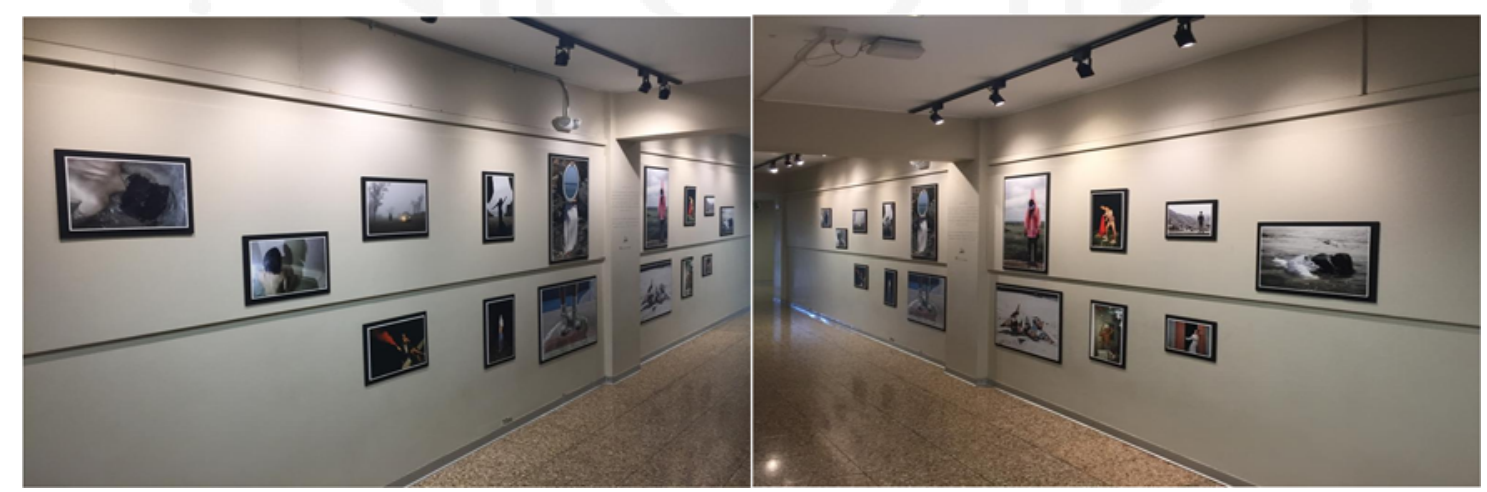

Elaboración propia

Es así como finalmente tomo la decisión de comenzar y terminar con un rostro oculto, de esta forma la exposición genera una sensación de continuidad que concentra la atención en el centro, donde la idea de refracción e identidad busca encontrar sentido en el receptor. Desde la ejecución y difusión se optó por actualizar el canal de red. Para ello, se 
presentó la opción de ingresar a Instagram en lugar de a Facebook y se presentó un logo en vinil debajo de la breve descripción.

La interacción se manifestó en que más de diez alumnos compartan historias en redes sociales interactuando con la exposición y hasta mostrando la cotidianidad con la que los alumnos habitan el espacio. Así, si bien no hay respuestas concretas respecto a la aprehensión, comprensión o percepción de la muestra, sí hubo un alto nivel de interacción que denota interés. Todas estas personas recibieron respuestas y fueron compartidas en aras de una mayor difusión. A continuación, adjunto algunas capturas de estas interacciones:

\section{Figura 3.6}

Evidencia de interacción en redes por vínculo de cuenta
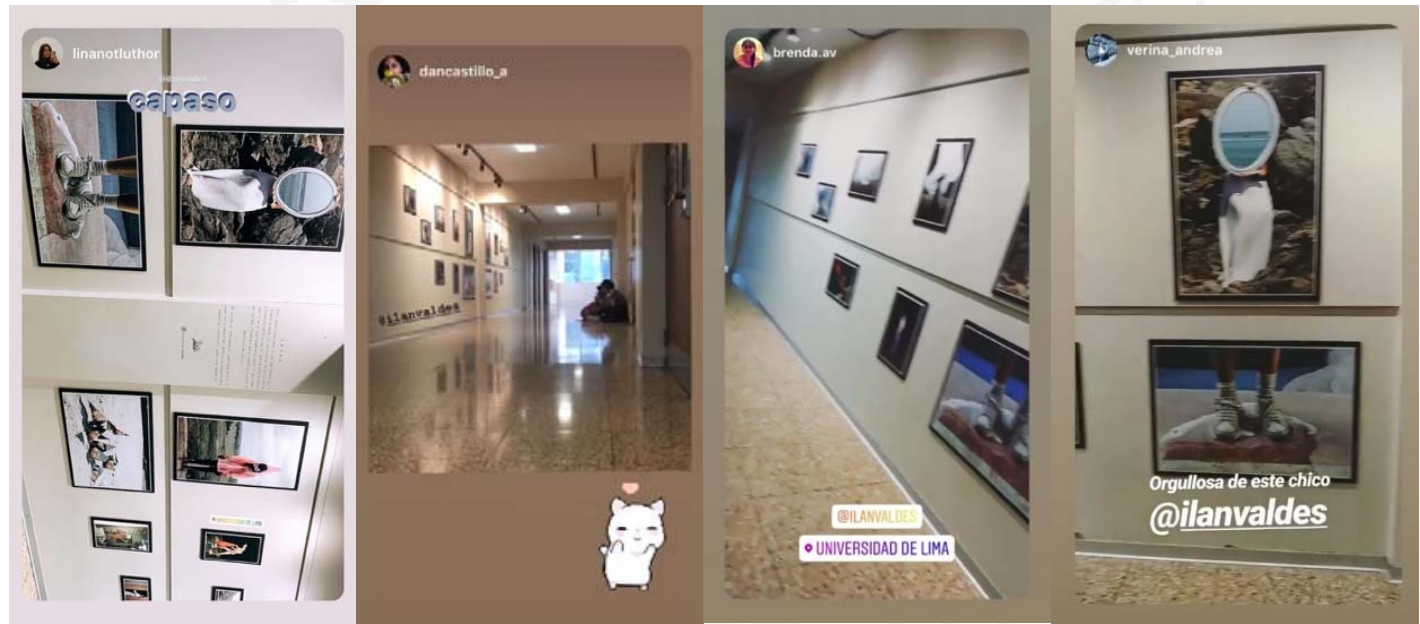

Elaboración propia 


\section{CAPÍTULO IV: LOGROS Y RESULTADOS}

\subsection{Entrevistas a Expertos}

Con el fin de validar las muestras, tanto de la exposición de 2017 (en aras a una mejor proyección del contenido), como la de 2019, se realizaron seis entrevistas a profundidad. Las primeras tres en 2017 a docentes de comunicación de la Universidad de Lima, donde se haría la muestra dos años más tarde. Los siguientes tres son entrevistados posteriores a la muestra de 2019, y arrojan luces respecto a las propiedades expandibles del proyecto y a las interrogantes que este postula.

\subsubsection{Entrevistas posteriores a la exposición de 2017}

Una vez realizada la exposición del 2017, se recogieron opiniones de expertos con la finalidad de mejorar y ajustar la exposición del 2019. Estas opiniones fueron tomadas en cuenta para la realización de la muestra incorporándose así una metodología más estructurada. Las anotaciones más importantes recogidas fueron las siguientes:

Nombre del experto: Ana Lía Orezzoli - Profesora de Géneros Fotográficos en la Universidad de Lima

Considera que, si bien hay un buen manejo de la técnica, es necesario pulir los antecedentes e identificar un criterio común para seleccionar a los modelos. A lo mejor se podría sistematizar el contenido un poco más. Recomendó revisar fotógrafos como Sally Man y Richard Avedon, así como investigar sobre el origen de los retratos. Recomendó revisar la historia del retrato con la finalidad de identificar la motivación y delimitar de mejor manera el hilo conductor de los sujetos a retratar.

Nombre del experto: José Guzmán - Profesor de Fotografía en la Universidad de Lima

Le gusta el proyecto, sin embargo, considera que se deben hacer ajustes con relación a la composición de los encuadres y uso de la técnica. Considera que la muestra se debe extender y que se debe definir una línea. Propone rearmar la muestra como una muestra personal. Para él, la línea visual es más importante que los sujetos a retratar y la muestra debería reflejar eso. 
Nombre del experto: Jorge Andrés Montalvo - Profesor de Casos de Investigación en la Universidad de Lima

Considera que se debe potenciar la idea de la coautoría y la participación del sujeto en la mirada del espectador: hablar de la reivindicación del rol del modelo. Es importante también adecuar un estilo estandarizado a cada serie independiente: que el estilo sea el hilo conductor en vez del sujeto. Sugiere buscar otra forma de validar el proyecto que no sea una muestra colectiva para desarrollar un proyecto como LÁTEX sin necesidad de seleccionar una cantidad específica, mostrando la totalidad de cada una de las series compuestas por cinco fotografías. Propone extender la validación a través de un formato de mayor alcance en redes.

\subsubsection{Entrevistas posteriores a la exposición de 2019}

Con la finalidad de recoger información respecto a los objetivos del proyecto, se entrevistó a tres profesionales del campo audiovisual posterior a la exposición de 2019. La información que se buscaba obtener responde a tres finalidades: la primera recoger el nivel de percepción general de los expertos sin conocimiento previo, la segunda explicar un poco del proyecto con el fin de validar los objetivos y, finalmente, obtener recomendaciones y percepciones de la muestra con el fin de explorar cambios dentro de las propiedades del proyecto.

Para llevar esto a cabo, se entrevistó a Manuel Bianchi, egresado de comunicaciones de la Universidad de Lima, quien ejerce como Director de Arte audiovisual de publicidad y largometrajes con el fin de recabar información específica de esta área. El segundo entrevistado fue Julián Amaru Estrada, director de foto miembro del DFP graduado con un MFA del American Film Conservatory, quien cuenta con más de veinticinco piezas como cinematógrafo. Por último, se entrevistó a Pedro Pablo Alayza, historiador de arte y licenciado de la facultad Arqueología e Historia del Arte en la Universidad Libre de Bruselas que ejerce el cargo de director del Museo Pedro de Osma. Se consideró oportuno contar con estos perfiles para componer una visión multidisciplinaria que contemple las distintas partes del proceso desde la técnica hasta el contenido.

Respecto al primer punto, y en relación a los comentarios generales y mensajes percibidos, Bianchi identifica a personas en juego con su entorno y una situación del plano real, metafórico e imaginario. Identifica la unidad que implica tener retratados en la construcción de lo que él considera una historia. Considera también que hay una intención lúdica por mostrar un abanico de momentos que, percibidos en conjunto, denotan una 
intencionalidad. Comenta que la serie reúne diferentes sensaciones que parten de sentimientos respecto a los modelos sin escapar de una visión de autoría.

Por otro lado, Estrada percibe un mundo fragmentado, mágico y duro que está basado en espacios reales y palpables. Habla de la magia dentro de lo real y se pregunta cuál fue la intencionalidad detrás de un tratamiento distinto de textura y color en cada fotografía. En este sentido, comenta lo novedoso que le parece escoger no poner toda la serie bajo un mismo hilo visual, sino más bien escoger foto por foto como si esa fragmentación se llevara a la curaduría y edición de la serie.

Los comentarios de Alayza, antes de la explicación de la serie, lo remontan a un mensaje que se recoge de la muestra en torno a la individualidad ligada a la soledad y la necesidad de afirmarse por otro. Menciona también que si bien parece que estos temas son paradójicos e incompatibles van de la mano. Identifica también un contraste muy fuerte entre ciertas imágenes y otras. Entiende, así, que es una búsqueda de múltiples lenguajes plásticos y de referencias mitológicas y visuales de arte contemporáneo que buscan explorar caminos y formas de mostrarlo.

Una vez recabada esta información, se procedió a compartir el abstract de la investigación para revelar la naturaleza exploratoria y colaborativa de la serie. Así, se buscó saber si la serie lograba explorar patrones artísticos desplegados en forma de representación individual para identificar así si la separación de retratados, las propiedades expandibles, la unidad y la exploración en torno al rol del modelo se habían logrado a cabalidad.

Bianchi encuentra patrones de individualidad como los altos contrastes que funcionan como metonimia. En relación a la representación individual considera que los fotografiados se encuentran en una lucha constante en la que se enuncia algo difuso. Respecto a la separación de los retratados considera que con la serie se pueden armar grupos que responden a un mismo universo con diferentes recursos que varían en forma de moods desde los valores técnicos. Aun así, encuentra unidad en el uso del cuerpo para comunicar y el uso del retrato para generar, desde el complemento y el artificio de la persona, a lo que este remite.

Cuando se le preguntó por las propiedades expandibles consideró que en las diferenciaciones estéticas entre los distintos actores, se manifiesta una dinámica compleja detrás de la colaboración. Vemos así, la unificación de dos visiones a las que no se puede 
ser esquivo. Bianchi agrega, por último, que en las variaciones encuentra que el artista le ha preguntado algo al modelo ya que, si todas las respuestas fueran iguales, las fotos mantendrían mayor unidad.

Estrada, por otro lado, considera que la serie logra usar a todos los retratados como forma de representación de lo que se busca comunicar. Ve los individuos como mecanismos para comunicar y considera que se evidencia en el uso de una escenografía que a veces esconde a los retratados y los deshumaniza en forma de colectividad. En relación a las propiedades expandibles, nota propiedades de un proyecto cotidiano comparable con el de Nan Goldin donde se busca retratar lo real, lo inmediato y lo instantáneo. Encuentra una unidad evidente en el uso del espacio, la utilería y el retrato de la realidad inmediata estilo snapshot.

Respecto a los objetivos del proyecto, Alayza comenta que es evidente la búsqueda de individualidad por grupo de fotografiados. Identifica también que no todas las imágenes se agrupan aisladas, sino que algunas van emparentadas por el lenguaje visual. Considera también que estos grupos son ventanas que abren a posibilidades de expansión hacia el desarrollo de historias gráficas. Un punto que considera no se logra del todo es la exploración del rol del modelo ya que prima la búsqueda de un lenguaje gráfico. Esta individualización considera que no se logra en todos los casos. Un ejemplo es que ciertas imágenes tienen, por ejemplo, un lenguaje cinematográfico mientras que otras un corte más editorial.

El tercer punto y último punto sobre el cual se buscó ahondar fue el de ajustes desde la técnica y el discurso. En ese sentido, Bianchi nota que se pudo llevar más al extremo la propuesta desde un enfoque hiperbólico que potencie la individualización sin restarle autoría. Considera que se pudo haber sido más tradicional con una unidad visual o línea estética más clara, aunque reconoce la intencionalidad en la propuesta y el grado de complejidad que busca que el espectador maneje.

Estrada recomienda, también, mantener una mayor unidad en el manejo de los espacios lumínicos. Considera también, sin embargo, que en la dualidad entre el uso y el no uso de los recursos se encuentra la unión estilística de la serie. En la combinación entre lo real, raído y carcomido, y los elementos fuera de lugar o mágicos encuentra un lenguaje estilístico y narrativo que funciona, en su opinión, muy bien.

Por último, Alayza sugiere retirar ciertas imágenes que restan unidad. Alayza considera que si se quitan una o dos imágenes hay una idea de soledad, individualidad y 
búsqueda contemporánea de falta de comunicación. Casi todas las imágenes para él responden a este patrón, y algunas se asocian así más a un planteamiento estético que a la búsqueda de una individualidad.

\subsection{Validación en Focus Group}

Con la finalidad de revisar los objetivos con el público objetivo se realizó un focus group el día 31 de octubre del 2019, donde se les presentó un boceto con lo que iba a ser originalmente la exposición, tal como se muestra en la primera disposición de la exposición del 2019. Se reunieron a cinco estudiantes, de los cuales cuatro asisten a la Universidad de Lima, con la finalidad de evaluar cada uno de los objetivos y recoger opiniones. Al momento de la ejecución de la dinámica, tres personas habían visto la muestra y dos no. La culminación de la exposición se dio dos semanas previas a la ejecución del focus group.

El participante 1 afirmó que, en general "Muchas de las fotografías que tienen un modelo tienen al foco como modelo mientras que en la muestra es una cosa más que forma parte de la construcción y que termina siendo un objeto de arte, pero no con una finalidad estética sino como una ruptura construida”. Con respecto a esto, podemos afirmar que el peso que tiene el modelo como figura logra una deconstrucción tal que propicia una mimetización entre el sujeto y el entorno. Puede que esto, a su vez, propicie la unidad general sin descartar el sesgo detrás.

El participante 4, por ejemplo, había visto previamente las series en redes sociales, lo que lo llevó a afirmar que “cuando las ves por separado, individualmente las series tienen sentido entre ellas, pero le parece complicado unir conceptualmente la totalidad de la serie”, en ese sentido el participante 2 agrega que "le costó en una primera instancia ver la serie como volúmenes”. Lo mismo sucede con el participante 3 que confirma gestualmente esta idea. Esto parece indicar que, al no haber un signo de constructo en serie adicional al que aparece en la descripción de la exposición, no es fácil para el espectador asociar esto como una manifestación individual sino como un conjunto.

A pesar de esto, sí hay un reconocimiento unánime de parte de los participantes respecto al trabajo por unidad y desarrollo de retratados individualmente. Esto hace pensar que, si bien no hubo un conocimiento previo en relación a la construcción de una serie, sí se identifica una intencionalidad interna que agrupa la disposición. El participante 2, en ese 
sentido, desarrolla: “Cuando las he visto juntas y he leído el texto las pude unir, pero si las desordeno aleatoriamente no pensaría que es un solo proyecto sino varios”.

El participante 1 agrega, adicionalmente: "Yo también lo había visto por partes, pero me dio la sensación que son personas diferentes que valen o dejan de valer lo mismo a pesar de las diferencias". El participante 5 responde a esto: "Hay una sensación general de personajes exhaustos en su límite o cerca, dentro de la disposición veo islas, por la iluminación, los colores y las locaciones que varían. Para mí el hilo conductor no es el caos sino el agotamiento".

Respecto a la disposición y cómo esta se traslada a la interpretación subjetiva, el Participante 4 menciona: "Al principio veo a una persona vulnerable tratando de escapar, luego algo más general con el espacio y el reconocimiento y finalmente un retorno a la misma sensación inicial”. El participante 1 complementa: “Veo un sentido de humanidad en el sentido que sientes que estás al borde, pero tomas rienda de las cosas y te das cuenta de que tienes que seguir adelante”.

Cuando se presentó la versión previa a la exposición del 2019 (Ver Figura 3.3), que terminaba con un paisaje, a ningún participante le gustó más, por considerar que iba en contra del concepto universal y cíclico. Adicionalmente, el participante 3 comentó que: "La versión previa tiene a los sujetos aislados, ahora es más fácil orientarse y puedo identificar los grupos”. El participante 5 agrega además que esta nueva disposición es más simétrica ayudando a dar unidad. El participante 1 también considera que "dista de lo que el proyecto quiere transmitir”. Finalmente, los cinco participantes consideran que la versión expuesta les hace más sentido.

Así, podemos resumir las opiniones afirmando que los estudiantes acordaron que la primera versión presentaba dos resultados fundamentales: El primero es que, al finalizar la serie con un paisaje en lugar de un retrato, se pierde la unidad buscada y pierde la posibilidad de observar la serie desde cualquiera de los extremos. El segundo es que se consideró que este final le daba una sensación de felicidad y esperanza que finalmente se optó por retirar. La segunda disposición (Figura 3.4), pareciera ayudar a generar tanto la sensación de unidad como la manifestación de un sentido individual y otro conjunto.

Otro descubrimiento fue la sensación compartida de que, si bien había una identidad conjunta detectable, el texto que acompaña la exposición es importante para concretar la unificación. Uno de los participantes nota una sensación de personajes “exhaustos y 
vulnerables” y llegando a un límite. Otra mencionó también que el modelo no se siente como el foco sino como un objeto construido que se diferencia desde el tamaño, el color y composición.

\subsection{Conclusiones}

Tomando en cuenta que el objetivo general fue realizar una serie fotográfica en la que cada sesión se diferencie de la anterior en tanto represente la "esencia” de lo que el individuo quiera transmitir manteniendo una unidad general en la muestra, los resultados evidencian que, al no haber hecho referencia directa al tratamiento serial de las fotografías, este se vuelve esquivo para el espectador. Así, no se cumple a cabalidad el objetivo de representar la esencia artificial del individuo, en tanto que esta responde a un discurso global y estético que no se centra exclusivamente en las aristas y facetas del retratado.

Esto se hace evidente cuando los participantes del focus group y los expertos entrevistados afirman que, si bien no hay una unidad tan evidente en la muestra como conjunto, sí es posible identificar "islas" que agrupan conceptualmente a los personajes construidos. Llama la atención cómo, sin embargo, a pesar de variar en el tratamiento, sí se concibe una conversación entre las fotografías desde conceptos calificados como “exhaustividad, rebeldía, libertad e incluso agotamiento”.

Así, el rol del modelo y la identidad pasan a un segundo plano y la unidad fragmentada comienza a ganar protagonismo. En ese sentido, se cumple el primer objetivo específico de encontrar patrones artísticos que se desplieguen en forma de una representación única por sesión. Si bien se reconocen en grupo las sesiones, los espectadores sí son capaces de reconocer distintos sujetos que dialogan en un mismo esquema. Tanto los profesionales entrevistados como los participantes del focus group son capaces de reconocer un tratamiento diferencial que trasciende al conocimiento serial y diferencial del tratamiento.

El segundo objetivo específico, el de construir un concepto con propiedades expandibles es, quizá, el que más se cumple a cabalidad. Habiendo realizado doce sesiones en aras de denotar una aparente distinción estética y conceptual que reflexione alrededor del sujeto en cuestión, se podría afirmar que independientemente de si se puede considerar un logro, constituye un reto. A medida que las sesiones se concretan, es más difusa la posibilidad de incluir elementos diferenciales lo suficientemente reconocibles como para constituir una serie en sí misma. Si a esto se le suma el reto del distanciamiento de una visión 
fotográfica incluyendo al fotografiado como eje temático y conceptual sin lugar a la repetición, es una tarea, si no imposible, muy compleja.

Sontag argumenta que las fotografías son un modo de apresar una realidad que se considera recalcitrante e inaccesible, de imponerle que se detenga (Sontag, 2015). La representación de la esencia, entonces, se presenta como una búsqueda colectiva que dista de ser una búsqueda perpetua por inmortalizar la identidad, sino más bien de reordenar la información disponible con la finalidad de explorar universos imaginarios que conversen entre ellos.

Así, pasamos al tercer objetivo específico: explorar y reflexionar alrededor del rol de los modelos y la identidad construida en la serie fotográfica. Para la realización de este proyecto, era imperativo que los participantes se cuestionen y se postulen la pregunta de quiénes son. Una pregunta sin respuesta que guiaría el proceso creativo y buscaría que se concrete en la forma de una muestra que invite al espectador a cuestionarse. Así, una pregunta encontraría su respuesta en la pregunta de alguien más.

La serie de Látex pasa de ser un proyecto que busca cuestionar la identidad del ser, a ser una invitación que se perpetua en el imaginario del espectador. La muestra de Látex no solo gira en torno al rol del modelo, sino que pasa a ser una crítica a la identidad compartida, a la idea de que nadie es único y a lo esencialmente inseparable que resulta el ser de su propia proyección.

\subsection{Lecciones aprendidas}

En lo que respecta a las lecciones aprendidas, en primer lugar, se rescata la opinión de Analía Orezzoli respecto al criterio de selección de modelos. En ese sentido, pudo haber un criterio más metodológico que responda a los objetivos en cuestión y no solo a la disponibilidad de los sujetos a retratar. En ese sentido, también es relevante tomar en cuenta que no había una relación previa con todos los fotografiados con la finalidad de que la reflexión respecto a la identidad diste de estar ligada a la relación y se enfoque en la identidad única de cada individuo.

Debido a la naturaleza exploratoria del proceso, si bien este inicialmente no contaba con un cuestionario, la incorporación posterior de este ayudó tanto al fotógrafo como al modelo a orientar la sesión. Aun así, la participación y aporte de cada modelo, al no estar estandarizada, variaba de acuerdo a la sesión afectando así la calidad de trabajo conjunto. 
Si bien la incorporación del cuestionario para la exposición del 2019 ayudó al proceso, también es importante mencionar que dada la naturaleza acumulativa del proyecto a medida que se incorporaban nuevos retratados era más difuso el eje diferencial. Así, es más fácil identificar y leer las sesiones como grupos en la primera fase del proyecto. Esto último se puede deber tanto a la naturaleza acumulativa ya explicada, como a la repetición de patrones en la identidad de los individuos fotografiados. Si bien esto puede ser perjudicial para la premisa del proyecto, también es verdad que aporta al sentido de unidad de la muestra.

Aun así, quizá la mayor lección aprendida -aunque a lo mejor no dista de ser una mera reflexión- recae en la imposibilidad de escapar del sesgo fotográfico. En ese sentido es importante notar cómo desde el siglo XX el modelo de estudio es sustituido por la apropiación estética (Chevrier, 2006). Así, este proyecto busca reivindicar el rol de un modelo que dista de ser un objeto de contemplación sino una herramienta expresiva donde la estética pasa a un segundo plano y se prioriza el mismo proceso de exploración.

Es imposible, sin embargo, hacer este distanciamiento a cabalidad dado que el proceso de captura fotográfica es dialéctico, evolutivo y en gran medida inconsciente. En ese sentido, no podemos escapar al aura ya que formamos parte de ella. (Ritchin, 2010). Resulta una tarea difícil, si bien el proyecto busca explorar distintas miradas fotográficas, que estas correspondan, a su vez, a la identidad de la persona retratada. Puede que un cuadro comparativo que diferencie los factores a tomar en cuenta para la composición y realización haya podido facilitar el proceso, sin embargo, delegar el descarte metodológico a la realización de las series pudo haber hecho que la naturalidad acorde a las necesidades, deseos y propias proyecciones de los retratados se vean afectados.

Esta extrapolación entre los recursos utilizados por los primeros retratados, dificultó el trabajo de los subsiguientes haciendo que su identidad esté condicionada a la realización de quien la precede. Es ahí donde los puntos en común cobran mayor interés e importancia demostrando que una metodología estricta y excesiva, si bien hubiera reducido el sesgo fotográfico, tampoco hubiera ayudado al objetivo general. Dicho esto, se considera que dicha exploración, si bien es ambiciosa en lo que pretende mostrar, no puede ser esquiva al discurso inconsciente de la muestra. 


\section{REFERENCIAS}

Arellano Marketing. (2017). Estudio Nacional del Consumidor Peruano. Recuperado de https://es.slideshare.net/ArellanoMarketing/estudio-nacional-del-consumidorperuano-base

Artnet. (2020). Nan Goldin. Recuperado de http://www.artnet.com/artists/nan-goldin/

Bencicova, E. (2017). Evelyn bencicova portfolio. Recuperado de http://evelynbencicova.com/

Cárdenas, N. (s.f.). "Foto de perfil". Recuperado de https://www.booooooom.com/ submissions/foto-de-perfil/

Cebrian, R. (2016). BIO. Recuperado de http://www.regiseco.com/rush.html

Chevrier, J. F. (2016). La fotografía entre las bellas artes y los medios de comunicación. Barcelona: Fotoggrafia.

Dagarslani, C. (2016). Serenity. Recuperado de http://www.candagarslani.com/ people/album/serenity/41.aspx

Gombrich, E. H. (2014). La historia del arte. China: Phaidon

Hang, R. (2017, Febrero 19). Radical photographer Ren Hang has a new book covering the last five years of naked bodies, octopi and not caring about what you think. Recuperado de http://www.hungertv.com/feature/radical-photographer-ren-hanghas-a-new-book-covering-the-past-five-years-of-naked-bodies-octopi-and-notcaring-about-what-youthnk/?utm_campaign=Echobox\&utm_medium=Social\&utm_source=Facebook\#lin k_time $=1485166451$

Instituto Nacional de Estadística e Informática, INEI. (2017). Evolución de la pobreza monetaria 2007 - 2017. Lima: Instituto Nacional de Estadística e Informática 
Jarvis, C. (2012). 17 Year Old Photographer Alex Stoddard His 365 Project. Recuperado de http://www.chasejarvis.com/blog/emerging-talent-17-year-old-alex-stoddard-365project/

Jiménez, P. (2016). Macarena Puelles (1993) - Malquerida. Recuperado de https://malqueridadice.com/2016/09/macarena-puelles-fotografa-peruana

Kane, A. (2016). How does it feel to be young, in love and in lust in Berlin? Recuperado de http://www.dazeddigital.com/photography/article/30114/1/matt-lambert-how-doesit-feel-to-be-young-in-love-and-in-lust-in-berlin

Lambert, M. (2019). Photo. Recuperado de http://www.dielamb.com/photo/

Mejía, S. (2016). Cuerpo y roles en la fotografía de moda. Recuperado de http://elpulpofoto.com/cuerpos-roles-la-fotografia-moda/

Mohammed, H. (2016). Self-portraits exploring the archetype of masculinity. Recuperado de https:/www.dazeddigital.com/photography/article/31285/1/self-portraitsexploring-the-archetype-of-masculinity

Mróz, M. (2016). Questioning Masculinity and Identity. Recuperado de https://www.ignant.com/2016/07/01/questioning-masculinity-and-identity/

Napolitano, L. (2017). Vivanne Sassen's stunning work comes to Chicago's Museum of Contemporary Photography. de JUXTAPOZ Sitio web: https://www.juxtapoz.com/news/photography/vivanne-sassen-s-stunning-workcomes-to-chicago-s-museum-of-contemporary-photography/

Oviedo, M. (2000). Los nuevos modelos de mujer y de hombre a través de la publicidad. Comunicar. Investigaciones Base de datos, 14, 208-217.

Pjörrt, I. (2016). Igor Pjörrt Documents The Curiosity and Naivety of Falling In Love. Recuperado de http://www.hungertv.com/feature/igor-pjorrt-documents-thecuriosity-and-naivety-of-falling-in-love/

Redacción PERU 21. (10 enero de 2018). Arte: 'Para Elisa', exposición individual de Macarena Puelles. Perú 21. Recuperado de https://peru21.pe/cultura/arte-elisaexposicion-individual-macarena-puelles-391445 
Press, S. (2016). Serenity By Can Dagarslani. Recuperado de https://www.ignant.com/2016/12/05/serenity-by-can-dagarslani/

Ritchin, F. (2010). Después de la fotografía. Mexico: 4 serieve.

Sánchez, J. (19 de julio de 2017). Las cinco principales tendencias del consumidor peruano. Gestión. Recuperado de https://gestion.pe/tendencias/cinco-principales-tendenciasconsumidor-peruano-139597

Sassen, V. (2020). UMBRA. Recuperado de https://www.vivianesassen.com/works/umbra/

Sontag, S. (2015). Evangelios Fotográficos. España: Debolsillo

Stoddard, A. (2019). Work. Recuperado de https://www.alexstoddard.com/work\#11

Stone, J. (18 de noviembre de 2015). Agape Charmani. Recuperado de http://artsheep.com/portraits-of-stephen-medeiros/

Napolitano, L. (2017). Vivanne Sassen's stunning work comes to Chicago's Museum of Contemporary Photography. Recuperado de https://www.juxtapoz.com/news/photography/vivanne-sassen-s-stunning-workcomes-to-chicago-s-museum-of-contemporary-photography/. 
ANEXOS 


\title{
Anexo 1: Formato de consentimiento firmado por todos los participantes del proyecto profesional
}

\author{
DECLARACIÓN JURADA DE AUTORIZACIÓN DE USO DE IMÁGEN
}

Por medio del presente yo, , identificado con el Documento de Identidad $\mathrm{N}^{\circ}$ certifico que he sido informado(a) con la claridad y veracidad debida respecto al ejercicio fotográfico realizado para el proyecto "Látex" de Ilán Valdés, donde me ha invitado a participar y donde se actuó consecuente, libre y voluntariamente como colaborador, contribuyendo a este de forma activa y cediendo así los derechos tanto para uso comercial como no comercial.

Se respetará la buena fe, la confiabilidad e intimidad de la información. Autorizo así a efectos de que hagan uso de mi imagen y los derechos conexos de explotación y exposición del material fotográfico. Adicionalmente, declaro que he sido adecuadamente informado(a) respecto a la forma de exposición y que no tengo reclamo alguno que efectuar a menos que su uso afecte mi integridad de imagen.

Finalmente, manifiesto que estoy en pleno uso de mis facultades al momento de firmar el presente documento y que reconozco las consecuencias y efectos de firmar el presente documento lo cual acepto libre y voluntariamente.

En fe de lo cual firmo la presente a los días del mes de del 2019.

NOMBRE:

DNI: 